Revista de Estudios Histórico-Jurídicos

[Sección historia del pensamiento político]

XLI (Valparaíso, Chile, 2019)

[pp. 467 - 501]

\title{
ENTRE LA HISTORIA DEL DERECHO Y LA TRADICIÓN CONSTITUCIONALES
}

[Between legal history and constitutional traditions]

\author{
Felipe Westermeyer Hernández* \\ Universidad de Chile
}

\begin{abstract}
RESUMEN
El objetivo de este trabajo es analizar el desarrollo de la historia constitucional en Chile, a la luz de las críticas y nuevos enfoques planteados por cultores de esta disciplina a nivel internacional. Para ello se analizan las principales obras de historia constitucional y se proponen nuevos temas a investigar, con el objetivo de determinar la posible existencia de una tradición constitucional chilena.
\end{abstract}

Palabras clave

Historia constitucional - tradición constitucional.
AbSTRACT

The objective of this paper is analyzing the chilean constitutional history's development under new criticisms and new focuses elaborated by new international academics. For this reason, we will analyze the principal works of constitutional history, and we will propose new topic for researching, in order to check the possible existence of a Chilean constitutional tradition.

\section{KeYwords}

Constitutional history - constitutional tradition.

RECibido el 2 de octubre de 2018 y ACEPTADO el 3 de julio de 2019

\section{INTRODUCCIÓN}

Al cumplirse 200 años de la promulgación de la Constitución de 1818, parece importante detenerse a revisar el desarrollo de la historia constitucional en Chile. Dicho texto, concebido con un carácter provisorio y sin mayor apoyo del director supremo, fue el primero que cumplió con todos los requisitos de una

*Legum Magister in Rechtswissenschaft. Ruprecht-Karls-Universität Heidelberg. Ayudante de Historia del Derecho. Facultad de Derecho, Universidad de Chile. westermeyer.felipe@ gmail.com. El autor agradece las correcciones efectuadas en Chile por los profesores Antonio Dougnac Rodríguez y Cristian Román, los materiales remitidos por el profesor Carlos Salinas Araneda, por su ayudante Ignacio Sánchez Bustos y por la bibliotecaria de la Facultad de Derecho de la Universidad de Chile, señora Gioconda Pulgar. Todos los errores son única y exclusiva responsabilidad del autor. 
constitución. En lo estrictamente jurídico, delimita claramente las competencias y límites de cada uno de los poderes del Estado y establece un catálogo de derechos individuales ${ }^{1}$. Restringe el poder estatal por medio de su distribución entre distintos organismos -consagrando límites al ejercicio de las facultades de cada uno de ellos- así como a través del reconocimiento de una serie de derechos inherentes al ser humano, demarcando un ámbito de autonomía individual en el que no puede entrar ${ }^{2}$.

Esa carta fundamental constituyó un hito: derrotados los realistas, es la ratificación jurídica de la intención de darse un ordenamiento acorde con los planteamientos ilustrados, independiente de los existentes en los demás territorios de la otrora corona hispana, coincidiendo con la declaración de la independencia ${ }^{3}$. Comenzará entonces la identificación entre constitución escrita, constitucionalismo y Estado independiente ${ }^{4}$.

Sin embargo, no es esta la ocasión de quedarse en el homenaje y en la apología. Más bien, es el momento de preguntarse cuánto se sabe acerca del desarrollo constitucional en Chile y de cómo se llegó a esa regulación y no a otra. La norma constitucional es solamente la culminación de un largo proceso de desarrollo dogmático y doctrinario cuyo estudio debería ser materia de historia constitucional. Esta disciplina posee un objeto de estudio que podríamos calificar -si se nos permite- como un tanto indeterminado. Su cultivo en Chile ha sido escaso

\footnotetext{
${ }^{1}$ Gran parte de estos son garantías penales. Al parecer, por su provisionalidad, se descuidó la regulación de los derechos políticos.

${ }^{2}$ El artículo primero de esa carta fundamental parte enunciando: “Los hombres por su naturaleza gozan $[. .$.$] ”.$

${ }^{3}$ Dicha declaración, en términos comparados, es de carácter tardío. Fue redactada por Juan Egańa, Manuel de Salas y Bernardo de Vera y se cree que también participó Bernardo Monteagudo. El texto original fue modificado en algunos puntos por O’Higgins, aparece fechado en Concepción el 1 de enero de 1818 y firmado en la ciudad de Talca el 2 de febrero de 1818, por el director supremo Bernardo O’Higgins y los ministros de gobierno, hacienda y guerra, Miguel Zañartu, Hipólito de Villegas y José Ignacio Zenteno, siendo jurada el 12 del mismo mes. Su tenor literal declara al mundo la voluntad del pueblo de Chile, en ejercicio de sus legítimos derechos, de independizarse de la monarquía y de darse la forma de gobierno que estime conveniente, retrotrayendo dicha declaración de voluntad al cabildo abierto celebrado en la ciudad de Santiago de Chile el 18 de septiembre de 1810. Frente a la actual polémica acerca del lugar su redacción y declaración se ha optado por seguir lo indicado por EyZAGUIRRE, Jaime, Historia constitucional de Chile (Santiago, Editorial Universitaria, 1959), p. 192.

${ }^{4}$ Hacemos hincapié en este punto pues tanto publicistas como iushistoriadores evitan referirse al sistema de gobierno existente entre 1810 y 1814, en el cual los afanes eran más bien autonomistas. No estaba claro qué forma de gobierno se quería adoptar, aunque ésta fuese de manera transitoria. No es extrańo, pues, que más de un grupo planteara fundar una monarquía constitucional en América. Prueba de ello es la Declaración de los Derechos del Pueblo de Chile y el proyecto constitucional de Egaña, de 1811, ratificado por el Cabildo de Santiago dos años más tarde. Casi todos los autores destacan el carácter autonomista de los primeros años. A mayor abundamiento y solo por mencionar algunos autores véase JOCELYN-HoLT, Alfredo, La independencia de Chile: tradición, modernización y mito ${ }^{2}$ (1992, Santiago, Ediciones DeBolsillo, 2009); Palma, Eric, Estado constitucional liberal católico en Chile (1812-1924). Nueva historia constitucional (Santiago, Orión, 2011); e Infante, Javier, Autonomía, independencia y república en Chile, 1810-1828 (Santiago de Chile, Ediciones del Centro de Estudios Bicentenario, 2014).
} 
y descontinuado a lo largo del tiempo. Tal vez por lo mismo los historiadores constitucionales no han realizado un esfuerzo colectivo para discutir su contenido, a diferencia de lo ocurrido en otras latitudes 5 . Para efectos de este artículo, creemos que sus finalidades son: a) desentrañar el proceso de elaboración de la norma de carácter constitucional; b) detectar cómo esta interactúa con los procesos políticos y sociales subyacentes; c) intentar entender cómo el constitucionalismo y las cartas fundamentales influyen en la realidad política e institucional del presente; y d) mostrar la forma en que ese proceso histórico ha configurado las actuales normas constitucionales. A ese rol se agrega otro de carácter interpretativo: e) determinar el alcance y contenido de los derechos y prácticas institucionales, a lo que muchas veces se da el nombre de tradición constitucional. Si bien esta última ha sido la mayor parte de las veces un recurso meramente discursivo, este concepto ha sido sistematizado por la doctrina y, en el último tiempo ha sido elevada a un carácter normativo por algunos tratados supranacionales.

Como se verá enseguida, partimos de la idea de que el derecho constitucional posee una dimensión nacional y otra internacional. Los grandes postulados y los principios gozan de reconocimiento y consagración global, pero su implementación es de carácter local. De ese modo, respecto a la primera de esas labores, el derecho constitucional tuvo un desarrollo propio en Hispanoamérica, tomando un derrotero distinto al de Europa o Estados Unidos, que estará marcado por el temprano surgimiento de la constitución escrita, el rechazo a la idea de monarquía -con la excepción de Brasil, algunos sectores rioplatenses y en menor grado, México-, la necesidad de fundar un Estado nacional, una temprana republicanización de los sistemas políticos, el reconocimiento del rol de la Iglesia católica en la sociedad y un ejecutivo muy fuerte ${ }^{6}$.

Doscientos años de constituciones escritas y la cinco veces centenaria tradición jurídica del ius commune en la América hispana dan mérito para ocuparse de cómo la constitución escrita y el constitucionalismo se han configurado en esta parte del orbe, qué particularidades han tenido, de qué forma han modelado

${ }^{5}$ Prueba de ello es la azarosa historia de la cátedra de historia del derecho constitucional, fundada en 1938, con el carácter de coadyuvante de la de derecho constitucional y reemplazada por la de historia de las instituciones políticas y sociales en 1967, tratándose de dos disciplinas completamente distintas.

${ }^{6}$ Sobre este último punto, para ver las diferencias y similitudes entre ambos procesos, puede hacerse el ejercicio de comparación de la caída de las monarquías en gran parte de Europa a comienzos del siglo XX con la institucionalización de los regímenes presidenciales en Hispanoamérica a partir de la década de 1810. Luego léase el estado de la dogmática histórico jurídica en Iberoamérica en lo que concierne al cambio y transformación de los sistemas jurídicos y compáresele con lo escrito, por ejemplo, en Alemania. Un buen ejemplo de ese desarrollo dogmático es, en el caso de la América española, la sustitución del monarca por el presidente de la República, con la denominación del titular del ejecutivo como rey sin corona y, en el caso de Alemania, el debate acerca de si el Reichspräsident de la República de Weimar era un Ersatzkaiser o no.

${ }^{7}$ Con ello nos referimos al derecho indiano y a los posteriores derechos patrios, que tomaron como fuente de inspiración tanto al primero como también a los códigos provenientes de Francia, Espańa y otros países europeos. Todos esos códigos no dejan de ser nuevas sistematizaciones del ius commune. 
su cultura jurídica y cuál ha sido su inserción en el derecho ya existente. Con el constitucionalismo ha sucedido algo similar a lo ocurrido con el ius commune, cuyas normas e instituciones estuvieron sujetas a particularidades y debieron adaptarse a otra realidad social, política y económica ${ }^{8}$.

Sobre la labor interpretativa, es oportuno tener presente que la transformación de las cartas fundamentales en textos vivos y vinculantes para todos los miembros de la sociedad y la incorporación de los tratados internacionales de derechos humanos al derecho constitucional han cambiado las relaciones de poder dentro de cada sociedad, reforzando la posición jurídica del individuo frente a ella y al Estado. Esta internacionalización de los derechos fundamentales viene de la mano de la búsqueda de criterios comunes para interpretar su sentido y alcance a nivel supranacional, con ánimo de encontrar concordancias entre los distintos ordenamientos nacionales. Uno de ellos, de reciente recepción, es la mencionada tradición constitucional ${ }^{9}$, cuya sistematización, a nivel de la Unión Europea, ha dado lugar al nacimiento de una nueva especialidad: "die europäische Verfassungsvergleichung", mezcla de historia constitucional, derecho comparado, derecho público y derecho europeo $^{10}$. La primera de estas disciplinas juega en ella un rol relevante, con un enfoque más jurídico que histórico. Importante resulta destacar que esta nueva perspectiva multidisciplinaria es la sistematización de una práctica de varias décadas por parte de la judicatura de la Unión Europea, que fundamentó su legitimidad ante los estados miembros en los derechos y prácticas nacionales, buscando un mínimo común entre ellos.

${ }^{8}$ En este punto importante es tener como ejemplo la denominación que la doctrina alemana hace ya varias décadas propuso para los sistemas constitucionales hispanoamericanos: la democracia presidencial. En resumidas cuentas se puede sintetizar esta proposición como una democracia cuya principal característica es un Estado unitario en los hechos, con una presidencia muy fuerte en cuanto a sus competencias gubernamentales y administrativas, en la que el presidente de la República desempeña el rol de jefe de Estado y de gobierno y a la vez cumple un importante rol como colegislador. Algunos académicos han conceptualizado este modelo como la democracia presidencial. Schultz, Judith, Präsidentielle Demokratie in Lateinamerika. Eine Untersuchung der präsidentiellen Regierungssysteme in Costa Rica und Venezuela ${ }^{2}$ (2000, Norderstedt, Books on Demand, 2002). Actualmente, el Instituto Max Planck für Völkerrecht und ausländiches Offentliches Recht propone la denominación de derecho constitucional común latinoamericano como un concepto que agrupa esas particularidades que lo diferencian del derecho público de otras partes del orbe.

9 Tras el fracaso de la constitución europea, los Estados miembros de la Unión homónima optaron por celebrar un tratado con el objeto de establecer un mínimo en materia de derechos fundamentales, denominado Carta Europea de derechos humanos. Dicho texto dice en el inciso $5^{\circ}$ de su preámbulo: "[...] La presente carta reafirma, respetando las competencias y misiones de la Comunidad y de la Unión, así como el principio de la subsidiariedad, los derechos reconocidos especialmente por las tradiciones constitucionales y las obligaciones internacionales comunes de los estados miembros [...]". Luego, en su artículo 52, inciso $4^{\circ}$, referido al alcance e interpretación de los derechos y principios, agrega: "En la medida en que la presente carta reconozca los derechos fundamentales resultantes de las tradiciones constitucionales comunes a los Estados miembros, dichos derechos se interpretarán en armonía con las citadas tradiciones".

${ }^{10}$ Para una sistematización al respecto, véase WEBER, Albrecht, Europäische Verfassungsvergleichung: ein Studienbuch (München, Verlag C.H. Beck, 2010). 
Más allá de la efectividad y certeza que este criterio interpretativo ${ }^{11}$ pueda proporcionar a la práctica jurídica ${ }^{12}$, o de si este será recogido en el futuro por otros sistemas jurídicos distintos del europeo, atingente es destacar que en este caso el legislador se ha hecho cargo de una realidad que vastos sectores de la doctrina han soslayado: las normas constitucionales suelen ser muy abstractas, abriendo un amplio espacio a la interpretación jurídica, que las vincula con la filosofía y la moral, sirviendo de puente entre la constitución y la cambiante realidad política y social ${ }^{13}$. Dicha labor hermenéutica echa mano del derecho comparado, la doctrina, la historia y las ciencias políticas, entre otras disciplinas. Así, el derecho constitucional adquiere una dinámica propia, tan importante como el texto de la carta fundamental. La última adquiere vida con su aplicación e interpretación, en el sentido más laxo de la palabra. Es el tenor literal junto con la praxis lo que da forma a la tradición constitucional, cuando esta es positivamente evaluada.

${ }^{11}$ Formulamos estos reparos pues todavía no hay un consenso en la doctrina acerca de cuáles son los contornos que permitan aplicar la tradición constitucional. Solo a modo de ejemplo Hans Jarass sostiene que las prácticas constitucionales no requieren contar con un plazo de vigencia tan extendido para constituir una tradición. Esas prácticas podrían tener un corto período de vigencia si entre los distintos Estados miembros de la unión hay criterios coincidentes. De todas maneras, su aplicación es restrictiva frente a los derechos consagrados por la Convención Europea de Derechos Humanos. Jarass, Hans, EU-Grundrechte: ein Studien-und Handbuch (München, Verlag C.H.Beck, 2005), p. 25. Thorsten Kingreen explica el criterio de tradiciones constitucionales como una forma de determinar el sentido y alcance de aquellos derechos que no están regulados en la Convención Europea de Derechos Humanos y en los que el derecho europeo tiene escaso desarrollo dogmático, como ha sido el caso de la libertad profesional y el derecho a trabajar. Tal aplicación significa no sólo recurrir al desarrollo histórico sino también hacer un ejercicio propio del derecho comparado. Callies, Christian; Ruffert, Matthias (eds.), EUVIAEUV Das Verfassungsrecht der Europäischen Union mit Europäischer Grundrechtecharta (München, Verlag C.H. Beck, 2011), pp. 2978-2979.

${ }^{12} \mathrm{La}$ inserción de este criterio admite dos posibles interpretaciones. Puede contribuir a establecer un minimum para todos los Estados miembros de la Unión Europea, sobre la base de que más allá de las particularidades, todos ellos constituyen una comunidad cultural y de valores. Pero también es posible entenderla como una manera de encauzar las diferencias a la hora de implementar el derecho europeo en los ordenamientos jurídicos nacionales, especialmente cuando a nivel constitucional existen diferencias con el derecho supranacional, o como una forma de evitar que la jurisprudencia aparezca demasiado ligada a la doctrina de alguno de los Estados miembros.

${ }^{13}$ Sólo a modo de ejemplo piénsese en el artículo 1 , inciso $1^{\circ}$ de la Constitución alemana, que incorpora el término Menschenwürde ('dignidad humana'). Dicho vocablo fue adoptado por la comisión redactora con la explícita intención de servir de puente entre la norma constitucional y las teorías de derecho natural católica y racionalista. Ello elevó a nivel constitucional un concepto filosófico con más de dos milenios de historia, lo que ha suscitado una serie de preguntas relacionadas con su naturaleza, alcance, fuerza vinculante y relación con los demás derechos fundamentales. Así existen hoy en día varias formas de explicar su actual contenido. Solo a modo de ejemplo, desde la teoría de las normas y desde un punto de vista histórico mencionamos las siguientes obras: Enders, Christoph, Die Menschenwürde in der Verfassungsordnung (Tübingen, Mohr Siebeck, 1997); SAnküHLER, Hans Jörg, Menschenwürde und Menschenrechte. Über der Verletzbarkeit und den Schutz der Menschen (Filderstadt, Verlag Karl Alber, 2014); Tiedeman, Paul, Menschenwürde als Rechtsbegriff. Eine philosophische Klärung ${ }^{2}$ (2007, Berlin, Menschenrechtszentrum Universität Postdam. Berliner Wissenschaft Verlag, 2010) y Pfordten, Dietmar von der, Menschenwürde (München, Verlag C.H.Beck, 2016). 
En los estrechos márgenes de este artículo no es posible responder las preguntas acerca de si existe en Chile una tradición constitucional, y en caso afirmativo, si es admisible la idea de una polifonía de tradiciones constitucionales ${ }^{14}$. Permanecemos escépticos frente a esta discusión. Las tradiciones jurídicas requieren un desenvolvimiento a lo largo del tiempo, por varias generaciones, con una expresión institucional que abarque parte importante del ordenamiento y las instituciones jurídicas. La tradición requiere, para ser tal, una práctica compartida y extendida en un número significativo de personas. La tradición no se puede personificar. Exige un grupo indeterminado de personas que conservan un saber y una manera de actuar. Su carácter es colectivo y anónimo. Por ello la tradición debe ser respaldada y documentada por estudios históricos, aspecto en el que la historiografía constitucional chilena se encuentra todavía muy al debe. Hasta ahora los estudios historiográficos sobre el siglo XIX que tienen alguna relación con esta materia siguen centrándose en las grandes figuras o los juristas de mayor relieve, cuyo valor es innegable pero aún no alcanzan a dar cuenta de cuán extendidas eran esas ideas ${ }^{15}$. Las figuras de la elite jurídica no necesariamente representan el sentir de la mayoría o de la mayoría de los que cumplen funciones de carácter jurídico o político. No descartamos su existencia. Por el contrario, proponemos una nueva forma de acercarnos a ese devenir constitucional, sugiriendo un nuevo enfoque de la historia constitucional y nuevos derroteros investigativos, hasta ahora preteridos por parte importante de la doctrina y la historiografía, a fin de poder responder estas preguntas. Por ende, es necesario revisar el estado de la cuestión y las principales obras escritas sobre el tema.

Para cerrar esta primera parte es necesario recalcar que no desconocemos que una de las características de este derecho constitucional ha sido la proliferación de normas constitucionales de corta o casi nula vigencia, lo que lleva a formular que en esta región del orbe importa más la promulgación de la carta fundamental que su cumplimiento y observancia. A ese respecto, sólo podemos responder que

${ }^{14}$ Pablo Ruiz-Tagle fue el primero en entrar en esta polémica, sosteniendo que si bien el constitucionalismo es el mayor esfuerzo colectivo realizado en Chile en materia jurídica, éste no alcanza para tradición. Fundamenta su aseveración en el hecho que es un esfuerzo individual, fragmentado, esporádico, sin haber una transferencia entre generaciones. CRISTI, Renato; Ruiz-Tagle, Pablo, La República en Chile. Teoría y práctica del constitucionalismo republicano (Santiago, Editorial LOM, 2006), pp. 79-80. De la opinión contraria es José Francisco García, quien en base a investigaciones propias y las de Patricio Zapata, sostiene la existencia de una tradición constitucional que provendría de la Pontificia Universidad Católica de Chile. Mientras Ruiz-Tagle usa como paradigma la obra de John Henry Merryman, García alude parcialmente al autor norteamericano, pero sobre todo a Guiseppe De Vergottini. Para efectos de este artículo, solo se puede indicar que es difícil tomar partido de una discusión en la que los replicantes no emplean ni el mismo paradigma ni el mismo esquema conceptual. Al parecer, el concepto de tradición constitucional de García es completamente distinto al de Ruiz-Tagle. GArcía, José, La tradición constitucional de la P. Universidad Católica de Chile (Santiago, Ediciones de la Pontificia Universidad Católica de Chile, 2017).

${ }^{15}$ Con esto aludimos, solo a título de ejemplo, a obras de como las de BraHm, Enrique, Mariano Egana: derecho y politica en la fundación de la República conservadora (Santiago, Ediciones Centro de Estudios Bicentenario, 2007). 
esperamos que algunos de los temas aquí planteados aporten algo de luz, con la finalidad de entender por qué tantas constituciones han sido flores de un solo día.

\section{ESTADO ACTUAL DE LA HISTORIA CONSTITUCIONAL A NIVEL GLOBAL}

Existe acuerdo en que el derecho constitucional ha sido, en mayor o menor grado, la manifestación jurídica de cuatro fenómenos sociales que se desarrollan en paralelo con la ilustración: la revolución industrial, la expansión del mundo europeo, el nacionalismo y el colonialism ${ }^{16}$. Logro del constitucionalismo y del derecho constitucional fue la universalización de nuevos paradigmas de igualdad ${ }^{17}$, participación política ${ }^{18}$ y libertad ${ }^{19}$; así como la propagación de una nueva idea acerca de la distribución del poder del Estado ${ }^{20}$ una nueva jerarquía entre las fuentes del derecho y el surgimiento de una nueva concepción de la relación entre política y derecho. Esas ideas tienen su expresión en el principio de separación de poderes, el reconocimiento universal de los derechos humanos y el surgimiento del sentido democrático.

De todos estos principios y transformaciones, la más relevante fue la primacía que adquiere la igualdad. La idea sobre ella existente en los siglos XVIII y XIX era la abolición de la sociedad estamental y la substitución de los gremios como factores determinantes del lugar que le corresponde a la persona dentro de la sociedad y

${ }^{16}$ Marquardt, Bernd, Los dos siglos del estado constitucional en América Latina (1810-2010): historia constitucional comparada (Bogotá, Universidad Nacional de Colombia, Facultad de Derecho, Ciencias Políticas y Sociales. Instituto Unidad de Investigaciones "Gerardo Molina"UNIJUS, 2011), I, p. 4.

${ }^{17}$ Igualdad que durante el siglo XIX fue entendida como la abolición de los estatutos especiales y que en el transcurso del siglo XX pasó a ser entendida como el reconocimiento de que ciertas características de las personas no autorizan un trato diferenciado. Del mismo modo, se reconoce que la existencia de desigualdades de hecho impiden el ejercicio de la libertad.

${ }^{18}$ Hablamos en este punto de participación política, pues el derecho constitucional europeo estuvo atravesado durante más de ciento cincuenta años por la discusión acerca del régimen de gobierno: monarquía o república. En el caso de la América hispana la discusión versó acerca de cuánta participación política correspondía a las masas en las nacientes repúblicas, y en cómo esta forma de gobierno podía poner atajo al militarismo y al golpismo.

${ }^{19}$ La primera concepción de libertad que postuló el constitucionalismo era como una afirmación de la esfera personal del individuo frente al Estado, la sociedad y otras personas, en la que nadie podía inmiscuirse. Dicha concepción buscaba limitar el poder estatal por medio de la consagración de los derechos fundamentales y la distribución del poder entre distintos órganos del Estado. Era una abstención, una libertad negativa. Luego de esta, pasó a entenderse, parcialmente, como un derecho a ciertas prestaciones estatales, a fin de hacer efectivo su ejercicio, en el marco de una sociedad industrial. Es decir, de una libertad contra el Estado se pasó a una libertad en y por el Estado.

${ }^{20}$ Hablamos de una nueva distribución del poder del Estado, atendido que la idea de los poderes del Estado independientes entre sí es inherente a una concepción laica del Estado y de la sociedad, la que se materializará en gran medida recién en el siglo XX. Nueva es porque, hasta ese momento, el poder estaba distribuido entre Estado, representado por la corona o el imperio y la Iglesia. En una sociedad de carácter religioso y confesional una organización controlaba los aspectos temporales y otra la dimensión moral del individuo. Ambas instituciones se controlaban entre sí mediante un sistema de frenos, contrapesos y estatutos especiales. 
cuál derecho le es aplicable. En vez de ello, se reconoce el valor del individuo en cuanto persona y portador de derechos. Cada estamento tenía instituciones que le eran propias y una organización única y diferente de la de los otros grupos sociales. Por ende, tal idea de igualdad significó la abrogación de toda la institucionalidad inherente a la organización estamental. Ello, unido a un fortalecimiento en el rol del Estado centralizador, llevó a la concentración de poder en muy pocas manos. Con toda razón se resalta que el derecho que surge del constitucionalismo y la codificación sea unificado y uniforme. El derecho se estatiza y legaliza.

El nuevo derecho no aceptó las diferencias per se. Por el contrario, las cuestionó y exigió una justificación para cada estatuto. El derecho no podía consagrar ninguna diferencia que no fuese racionalmente justificada. Tal proceso implicó la anulación de la comunidad como creadora de derecho ${ }^{21}$. Hasta ese momento cada comunidad detentaba un estatuto propio, cuya justificación era la mayor parte de las veces las circunstancias, la historia y la tradición. En consecuencia, tuvo lugar una nueva sistematización de las fuentes jurídicas, en la que la costumbre se vio desplazada frente a códigos y constituciones. Hasta ahí llega el consenso. Esa re-sistematización ha sido entendida como el surgimiento de un nuevo derecho, cuyas características, procedimientos y métodos revestirían un carácter completamente innovador respecto a lo que era la ciencia jurídica hasta el siglo XVIII. Dicha corriente fundamenta este planteamiento en la conocida dicotomía entre la sociedad del Antiguo Régimen y el derecho moderno.

Sin embargo, no se trata de un proceso uniforme, sino dinámico y sujeto a una serie de situaciones que muestran que este fenómeno está marcado por la diversidad. La institucionalización y recepción de estos valores no ha sido de carácter lineal, sino sujeto a avances y retrocesos. En cada país la transformación de ese derecho tuvo tiempos, lugares e hitos distintos. Revolución y reforma son dos vías que están en permanente interacción. Mientras una suena más, la otra fue la regla general. Las revoluciones propiamente tales fueron pocas y excepcionales. Por esa razón, plantear hoy en día que las transformaciones se dieron a rajatabla parece un poco osado.

Pese al consenso que generan estas transformaciones, a la universalidad adquirida por los derechos humanos a nivel de organismos internacionales y al carácter universal de autores como Montesquieu, Rousseau, Voltaire, Kant, Burke y Sieyes -por solo nombrar a algunos-, hacen falta obras que problematicen este proceso, desde una perspectiva holística y de carácter global. Casi todos los Estados occidentales se han dado a sí mismos constituciones escritas, pero estas no necesariamente se corresponden con las ideas del constitucionalismo. Por otra parte, es inconcuso que el derecho constitucional ha estado en permanente evolución. En los siglos XIX y XX se han agregado otros autores tan influyentes como los dieciochescos. Baste mencionar a los norteamericanos Alexander Hamilton y James Madison,

\footnotetext{
${ }^{21}$ Hacemos esta aseveración en este acápite de corte general, pues en la aplicación de esta premisa no se dio con igual intensidad en todas partes. El caso más emblemático de anulación de las organizaciones sociales se dio en Francia, con la llamada ley Le Chapelier sobre prohibición de asociaciones de trabajadores de 14 de junio de 1791. En los casos de España e Hispanoamérica la representación corporativa coexistió con las nuevas formas de representación individual.
} 
a los alemanes Georg Wilhelm Hegel, Karl Marx y Carl Schmitt, al austríaco Hans Kelsen y los franceses Benjamin Constant y Raimond Carre de Malberg.

Por lo demás, han sido nuevos fenómenos sociales, como la cuestión social, la revalorización de las minorías étnicas y las violaciones masivas a los derechos humanos, los que han marcado el devenir de las ciencias jurídicas en general y del derecho constitucional en particular. Las respuestas tanto institucional como doctrinaria han determinado la manera en que este derecho es entendido y aceptado. Ello forma tradiciones. Desde esa perspectiva son útiles las obras de Maurizio Fioravantti y Bernd Marquardt, pues ofrecen un esquema global, que tiende a problematizar la manera en que ha sido entendida la historia constitucional, abriendo paso a nuevos derroteros investigativos.

Fioravanti da al concepto de Constitución y las manifestaciones que este ha tenido en las distintas épocas de la historia de occidente. Señala que "para nosotros han existido varias doctrinas de la Constitución, con la intención, siempre recurrente, de representar en el plano teórico la existencia o la necesidad de una Constitución, de un ordenamiento general de la sociedad y de sus poderes [...] cada época tiene caracteres constitucionales fundamentales y cada una de ellas ha planteado en la teoría y en la práctica, de manera peculiar y original el problema de la Constitución, del ordenamiento general de las relaciones sociales y políticas" 22 . La propuesta del académico florentino no significa que exista una relación de continuidad entre las distintas concepciones y épocas, pero ello no implica descartar la influencia de los ordenamientos y culturas jurídicas anteriores al siglo XVIII en los nuevos sistemas jurídicos surgidos allí. Dicha pervivencia se da tanto a nivel normativo como de doctrina y cultura jurídica, como por ejemplo los usos, práctica y el lenguaje administrativo y judicial. No deja de ser notable cómo los sistemas jurídicos sobreviven con otras formas por medio de la estructura de valores que en ellos se anidan. Cuando el nuevo sistema jurídico logra generar su propia estructura de valores, y esta es efectivamente recogida por parte importante de la sociedad, solamente ahí puede señalarse que se está ante algo nuevo ${ }^{23}$. Fioravanti sostiene que cada época posee caracteres constitucionales propios y fundamentales, y ha planteado de manera peculiar y original, tanto en la teoría como en la práctica, el problema de la constitución, esto es, del ordenamiento general de las relaciones sociales y políticas ${ }^{24}$. Respecto a la época moderna, sistematiza ese carácter peculiar en los siguientes puntos: soberanía contra la constitución, revoluciones, constitución contra la soberanía, Estado y Constitución, y democracia y Constitución ${ }^{25}$.

Coincidimos con el planteamiento del profesor Fioravanti. Su propuesta metodológica incorpora aspectos hasta ahora preteridos; sin embargo, su análisis se focaliza en el viejo continente. La realidad americana ofreció problemas poco conocidos en Europa. El derecho no sólo cambia con el paso del tiempo sino que

\footnotetext{
${ }^{22}$ Fioravanti, Maurizio, Constitución: de la Antigüedad a nuestros días ${ }^{2}$ (2002, Madrid, Editorial Trotta, 2007), pp. 12-13.

${ }^{23}$ Ibíd., p. 12

${ }^{24}$ Ibíd., p. 13

${ }^{25}$ Ibíd., pp. 71-164.
} 
también de acuerdo con la realidad social en la que debe regir. Ahí radica su doble dimensionalidad, que en palabras del profesor Bernd Marquardt ha sido hasta ahora poco sopesada. Marquardt enriquece la perspectiva de Fioravanti, al sostener que la historia universal del Estado constitucional republicano-democrático, sus raíces concretas, los países protagonistas, sus ritmos, sus desafíos, transformaciones y su difusión en el espacio global son temas casi ignotos ${ }^{26}$. Por nuestra parte, estimamos que esos son aspectos que dan lugar a tradiciones constitucionales, a los que la historia constitucional también debería abocarse. El profesor Marquardt fundamenta su afirmación en que, pese al volumen de la literatura existente, se pueden observar tres grandes falencias: i) predominan los enfoques nacionales y una multitud de historiografías constitucionales aisladas; ii) la perspectiva comparada se centra en tres modelos: Inglaterra, Francia y Estados Unidos; y iii) el estudio del constitucionalismo se centra en la recopilación de textos sin la adecuada contextualización socio-jurídica y en obras políticas teóricas con poco análisis de las fuentes primarias ${ }^{27}$.

Agrega Marquardt que los enfoques nacionales desfiguran ciertos procesos para justificar el camino propio y ocultan aspectos como la interdependencia transnacional y las olas internacionales, dejando los fenómenos de recepción, adopción y difusión escondidos e invisibles ${ }^{28}$. Asimismo, los tres modelos citados llevan a una idealización que no se condice con la realidad histórica de ese tiempo, citando el caso del constitucionalismo republicano francés, aparecido en 1789, pero recién firme en 1870 con la caída de Napoleón III ${ }^{29}$. En el mismo sentido, plantea que el protoconstitucionalismo inglés entre los siglos XIII y XVIII no era cualitativamente muy distinto del vigente en esas centurias en el Sacro Imperio Romano Germánico o en Polonia ${ }^{30}$. La alta valoración del primero es producto de la obra del barón de Montesquieu ${ }^{31}$.

En el último aspecto de esa triple crítica, la historia constitucional ha tenido como fin legitimar e interpretar la norma. Dicho enfoque, a nivel internacional, se explica tanto por la influencia de la romanística como por el iuspositivismo, sin mayores nexos con la sociedad concreta ${ }^{32}$. A ello se debe agregar la intromisión de las ciencias políticas, disciplina que hoy en día es independiente de las ciencias jurídicas $^{33}$. El citado profesor propone que la historia constitucional vuelva a la historia del derecho, tomando en cuenta las condiciones de la norma, su influjo en la sociedad, ampliando las fuentes primarias, considerando las actas oficiales de los procesos constituyentes, los proyectos, las leyes y decretos que concretizaron las normas constitucionales, la jurisprudencia, los tratados internacionales, actos

\footnotetext{
${ }^{26}$ Marquardt, Bernd, cit. (n. 16), p. 5.

${ }^{27}$ Ibíd., pp. 5-6.

${ }^{28}$ Ibíd., p. 10.

${ }^{29}$ Ibíd., pp. 11-12.

${ }^{30}$ Ibíd., p. 13.

${ }^{31}$ Ibíd., p. 13.

${ }^{32}$ Ibíd., pp. 15-16.

${ }^{33}$ Ibíd., p. 18.
} 
administrativos, la opinión de la prensa, las imágenes históricas y la opinión de los extranjeros ${ }^{34}$.

Nos hacemos eco de estas críticas. En Hispanoamérica, durante la primera mitad del siglo XIX surgió la necesidad de fundar un derecho propio, de carácter patrio, cuya principal fuente fuese la ley, otorgándole relevancia al derecho comparado como fuente material. La apertura comercial, las nuevas relaciones diplomáticas y la posibilidad de viajar sin sujeción a una excesiva burocracia multiplicaron las posibilidades de interacción entre distintos ordenamientos por vía de códigos y constituciones. Realizar la exégesis de cada norma se volvió mucho más complejo, pues cada constitución y cada ley contó desde ese momento con varios modelos en los que inspirarse. Rara vez se optó por la copia textual de una constitución o un código. En el siglo XIX, la América hispana vivenció un proceso de recepción, copia y adaptación de textos jurídicos no solo europeos -preferentemente españoles y franceses- o estadounidenses, sino también y sobre todo iberoamericanos ${ }^{35}$. Cada uno de los nuevos países estaba en contacto con los otros, sabía de sus dificultades y las formas de solucionarlas. De ahí que los enfoques nacionales impidan ver cómo se desenvolvió este proceso a nivel global.

Sin embargo, pese al número de países que representaba esta región del orbe, su cantidad de habitantes y su contacto económico y comercial con el viejo continente, más de un tratadista de derecho público de importancia global y asiduamente leído y citado en el mundo hispano parlante omite en sus obras de teoría del Estado a esta región, pese a exhibir casi un siglo de desarrollo jurídico e institucional al momento de escribir sus libros ${ }^{36}$.

Por otra parte, el proceso de sustitución de un derecho de carácter local por otro nacional, uniforme y unificador implicó para las ciencias jurídicas y políticas la necesidad de articular un discurso que fundamentase y pudiese legitimar los cambios propuestos. Este discurso provenía principalmente de los tres países citados por Marquardt. Ellos fueron considerados como los paradigmas de valores tales como la libertad, la igualdad y la fraternidad. Punto conflictivo fue que ese discurso debía adaptarse a realidades sociales distintas a las de esos arquetipos. Las realidades sociales en las cuales se introdujeron las constituciones eran muy

\footnotetext{
${ }^{34}$ Ibíd., pp. 18 ss.

${ }^{35}$ Sólo a modo de ejemplo, para el derecho civil, GuZmán Brito, Alejandro, La codificación civil en Iberoamérica. Siglos XIX y XX (Santiago, Editorial Jurídica de Chile, 2000). Para el proyecto de Constitución federal chileno véase Galdames, Luis, Evolución constitucional de Chile. 1810-1925 (Santiago, Imprenta y Litografía Balcells, 1925), y Carrasco, Sergio, Génesis y vigencia de los textos constitucionales chilenos ${ }^{3}$ (1983, Santiago, Editorial Jurídica de Chile, 2002).

${ }^{36}$ Nos referimos al caso de Georg Jellinek, quien, en su curso del año 1896, al momento de explicar la naturaleza de las repúblicas modernas, sostiene que estas son fruto de las ideas calvinistas, reconociendo tres formas de república: las absolutamente democráticas (cantones suizos); las democracias representativas y aquellas que combinan la democracia directa y la representativa. Destaca que en la segunda puede existir un ejecutivo que recaiga en una sola persona y que en el caso de Estados Unidos se sigue el modelo del monarca británico. Jellinek observa que en general el ejecutivo en las repúblicas era un monarca disminuido. En su obra no hay ninguna mención a las repúblicas americanas. JELLINEK, Georg, Vorlesungsmitschrift von Max Ernst Mayer aus dem Sommersemester 1896 (Tübingen, Mohr Siebeck, 2016), pp. 76-79.
} 
distintas en la América Española, Norteamérica, la Europa Atlántica y la Europa Central. De ese modo, la concretización de ideales como la libertad, la igualdad, la fraternidad; el sometimiento del poder al derecho y la justicia y la educación y civilización del hombre como pilares de los ideales ilustrados exigió el cumplimiento de objetivos distintos en cada continente y la confección de discursos legitimatorios que interpretasen las carencias de cada región.

Eso hace explicable que el discurso y la reforma social se legitimasen a través de dos caminos: o por un engarce con la tradición o por la ruptura con ella. Casi todas las sociedades adoptaron en parte uno y otro. No hubo una sola forma de implementar el constitucionalismo ${ }^{37}$, aunque no pocas historiografías se centran de manera excesiva en la revolución, siendo que los sistemas jurídicos pocas veces nacen de una. Ésta puede ser solo el primer paso, pero poco más que eso.

El surgimiento de las constituciones escritas coincide en la América indiana ${ }^{38}$ con la independencia de los reinos que integraban la corona; en la Europa central, con el interés de transformar las antiguas naciones en Estados, y en España y Francia, con una crisis de legitimidad de la monarquía. De esa forma el constitucionalismo se identificó prontamente con la historia y con el derecho patrio, perdiendo la perspectiva global. El derecho constitucional pasó a ser solo parte de ordenamientos jurídicos patrios legalizados y estatizados.

Por último, el usar a Francia, Estados Unidos e Inglaterra como los paradigmas a través de los cuales se puede analizar el mayor o menor desenvolvimiento del derecho público en general y del constitucional en particular obscurece importantes aspectos de estas ramas jurídicas. Tal situación niega originalidad a otros sistemas constitucionales, conduciendo a falsas interpretaciones respecto del origen y fin de diversas normas, comprensibles solamente de acuerdo a desarrollos dogmáticos nacionales pero ininteligibles si se las aprecia desde la óptica jurídica francesa, británica o norteamericana ${ }^{39}$. Centrarse únicamente en esos países como modelos constitucionales representa también un anacronismo, pues desde mediados del siglo XIX han entrado a jugar un rol importante en la doctrina y el Derecho Constitucional otros países como Italia y Alemania ${ }^{40}$.

${ }^{37}$ Por ejemplo, el constitucionalista José Victorino Lastarria buscó fundamentar moralmente la imposición del derecho constitucional y del constitucionalismo en el cristianismo. LASTARRIA, José Victorino, Historia constitucional de medio siglo (Valparaíso, Imprenta El Mercurio, 1853), p. VIII. Del mismo modo en Oyarzún, Luis, El pensamiento de Lastarria, en VV.AA., Estudios sobre José Victorino Lastarria (Santiago, Ediciones de la Universidad de Chile, 1988), p. 175.

${ }^{38}$ Los conceptos derecho y América indiana se entienden como expresión de una determinada manera de comprender la conquista y la colonización española en América, pero también como una expresión para ilustrar el derecho europeo vigente en América durante la monarquía: el Indiarum Iure, plasmada por Juan de Solórzano y Pereyra en su famosa obra del mismo título.

${ }^{39}$ A modo de ejemplo puede citarse la consagración constitucional de la confesionalidad del Estado. Dicha cláusula tuvo por objetivo dar garantías a amplios sectores de la población de que se continuaría con las políticas de ayuda y asistencia de la Iglesia católica en cuanto institución de beneficencia, evabgelización y educación. Sin embargo, tal disposición en ningún caso fue entendida por los juristas chilenos como una persecusión contra quienes profesasen otros cultos. A mayor abundamiento, véase Egaña, Juan, Memoria politica sobre si conviene en Chile la libertad de cultos (Caracas, Imprenta Devisme, 1829).

${ }^{40}$ Fioravanti, Maurizio, cit. (n. 22), pp. 142 ss. 
Otra consecuencia del enfoque predominante es la omisión de un análisis de los textos constitucionales de acuerdo a la época en que fueron escritos. El desarrollo del derecho constitucional, entendido en un sentido restringido ${ }^{41}$, se puede dividir en etapas tomando en consideración cuál haya sido la relación entre las constituciones y la democracia. A este respecto, el profesor Fioravanti habla: a) de la época de las revoluciones, b) de la época de la constitución contra la soberanía y c) de la época de la democracia y la constitución, contando cada una con constituciones emblemáticas ${ }^{42}$. Aunque esta periodificación es formulada conforme a cánones europeos, los contenidos de las cartas fundamentales iberoamericanas se podrían ajustar parcialmente a esa clasificación, no obstante no haber correspondencia exacta entre los hitos que marcaron los cambios de época ${ }^{43}$. Desde un punto de vista histórico, el vínculo entre constitución y democracia presenta un desarrollo sinuoso y ambivalente. Lo que en este punto diferencia a la América Hispana -con la excepción de México- del resto de Occidente fue que la discusión entre república y monarquía fue comparativamente muy corta. Si en Europa esta discusión partió en 1789 y se zanjó poco después del término de la Segunda Guerra Mundial ${ }^{44}$, en nuestro caso duró a lo más 15 años.

Pero esto no significó que en la América hispana las discusiones relacionadas con la forma de gobierno y la participación política quedasen zanjadas en un modelo de gobierno. La tríada constitución, soberanía y democracia se manifestó por medio de la todavía no bien resuelta definición entre república, autoritarismo, democracia, dictadura y participación política de las masas. No por casualidad hay quienes afirman que la América hispana todavía está buscando su propio orden. En este mismo sentido, tampoco se puede dejar de considerar que las transacciones ideológicas son la regla en los textos constitucionales. Éstas siempre tienen un carácter temporal y local. Sobre la última crítica que formula el profesor

${ }^{41}$ En este punto, entendemos derecho constitucional en sentido restringido respecto de la expresión clásica; es decir, aquella que nació en el siglo XVIII y se desarrolló en los siglos posteriores hasta nuestros días. En este trabajo, cuando se hagan alusiones al protoconstitucionalismo o a las constituciones en otras épocas históricas, se mencionará expresamente.

${ }^{42} \mathrm{El}$ profesor Fioravanti sitúa como los hitos que marcan los cambios de etapa el Congreso de Viena de 1815, en el que la Constitución pasa a ser entendida como un instrumento jurídico que enmiende al pueblo, pues este no es capaz de discernir qué es lo mejor para sí, y la Constitución de Weimar como el advenimiento de la concepción democrática de la Constitución.

${ }^{43}$ Nos atrevemos a formular que para la América española, la época de las revoluciones corresponde al corto período que va desde la invasión napoleónica a la Península Ibérica hasta más o menos los años 1814-1815, la segunda desde estos últimos años hasta el fin de la primera guerra mundial. La tercera época es más difícil de determinar pues mientras la doctrina decía una cosa, la realidad política del continente decía otra. No obstante, la América hispano parlante puede jactarse de que su primera constitución de corte social, la de Querétaro, es anterior a la de Weimar.

${ }^{44}$ Fijamos como fecha junio 1946, en la que Italia, mediante un plebiscito decidió si su forma de gobierno era una monarquía o una república. Dicho plebiscito fue el último acto por el cual un pueblo decidió abiertamente cuál de estas formas de gobierno adoptaba. A partir de esa fecha no ha habido grandes cambios en esta materia en Europa. Los estados han conservado la forma de gobierno que tenían en esa fecha. 
Marquardt, creemos que, para el caso chileno, amerita revisar autor por autor, como se hará enseguida.

Una consideración metodológica que merece un párrafo especial es el análisis de los discursos legitimadores del constitucionalismo y el uso que ellos hacen de la historia y de las experiencias en ese momento conocidas en otras partes del mundo. La doctrina publicista latinoamericana del siglo XIX se sabe y se siente protagonista de un proceso, pero se percibe en la periferia. Sabe que la emancipación política es un punto de partida; pero que en ningún caso ha significado un cambio sustantivo en las condiciones de vida ni en las estructuras sociales y mentales de esa época. Por eso importa rescatar las referencias a la historia y a las ideas imperantes acerca Europa y Latinoamérica. En el caso de la América hispana se asistió a la segunda leyenda negra antiespañola. Todos los males y problemas que aquejan a los nuevos países eran producto de la cultura hispana y de la herencia colonial. En muchos casos, el manejo de la historia estuvo sujeto a las anteojeras políticas y se supeditó a un determinado proyecto ideológico.

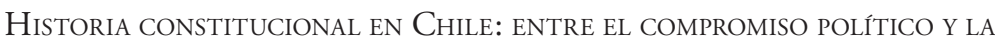 FORMULACIÓN CIENTÍFICA ${ }^{45}$}

\section{Las principales corrientes interpretativas ${ }^{46}$}

En Chile, la historia constitucional ha tenido un desarrollo completamente independiente de la historia del derecho. Mientras la última disciplina aparece en los planes de estudios de derecho recién en $1901^{47}$, los primeros trabajos sobre la primera datan de la década de 1840 . No es casual que la historia constitucional haya sido una de las primeras disciplinas jurídicas que tuvo desarrollo en Chile. La emancipación política requería una justificación, cuya manifestación jurídica eran precisamente las constituciones.

Pese a ese temprano despegue, su desarrollo presenta un carácter discontinuo y, por qué no decirlo, en más de una ocasión algo tendencioso. Es una historia constitucional que en varias oportunidades se ha construido y reconstruido desde las categorías, ideas y perspectivas del tiempo presente, centrándose muchas veces

\footnotetext{
${ }^{45}$ En las últimas tres décadas, la producción científica de los publicistas chilenos ha sido enorme, teniendo muchos artículos y libros de derecho público algún alcance histórico constitucional. En este sentido, en aras de lo que se plantea en el penúltimo capítulo de este artículo, se han considerado solo aquellas obras cuyo tema principal es la historia constitucional. También se han excluido interesantes modelos interpretativos, como es el caso del constitucionalismo republicano, representado, entre otros, por Vasco Castillo, Renato Cristi, Sofía Correa, Alfredo Jocelyn- Holt, Carlos Ruiz Schneider y Pablo Ruiz- Tagle, por estimar que el siglo XIX sigue siendo para efectos iushistoriográficos desconocido.

${ }^{46}$ El criterio para hacer esta distinción no viene, para efectos de este artículo, dado por la escuela o la metodología historiográfica a la que los autores citados adhieren, sino exclusivamente por su postura frente a la manera en la que Chile se organizó a partir del comienzo del proceso de emancipación política y por el mayor o menor énfasis en un sistema de libertades y/u orden. Se han exxcluído las obras que versan sobre esta temática que no pioseen un carácter jurídico.

${ }^{47}$ Dicho año fue suprimida la cátedra de Derecho canónico en la Facultad de Derecho de la Universidad de Chile, para ser reemplazada por Historia del derecho.
} 
solo en los textos que fueron denominados 'constitución'48 dando por sentado que la idea y los fines de la constitución han permanecido invariables a lo largo del tiempo, conformándose con un análisis exegético y descriptivo de la norma. Se olvida que el derecho es un sistema en constante y lenta evolución. El derecho cambia de modo similar al lenguaje. Esa historia constitucional, además, no le ha dado la merecida importancia a otras fuentes jurídicas, como la doctrina, la jurisprudencia o las leyes que regularon instituciones de carácter constitucional. Comparativamente, las obras de historia constitucional son pocas. La mayor parte de ellas, artículos o capítulos en tratados generales de derecho público. Ello no obsta a que estas puedan ser agrupadas, a grosso modo, en dos tendencias: liberal y conservadora ${ }^{49}$.

La corriente liberal rescata el período que media entre 1823 y 1830 , considera que la obra cúlmine del constitucionalismo chileno es la constitución de 1828, valora el influjo francés y norteamericano y hace sinónimos la voz progreso con la superación de la herencia hispana ${ }^{50}$. En general, se muestra muy crítica de la Constitución de 1833 y de la figura de Diego Portales. Representa una concepción del derecho constitucional como una ruptura con el viejo orden. Entre sus principales representantes, historiadores y abogados, se puede citar a Manuel Carrasco Albano, José Victorino Lastarria, Diego Barros Arana, Domingo Santamaría, Isidoro Errázuriz, Benjamín Vicuña Mackenna, Alcibíades Roldán, Miguel Varas Velásquez, Alberto Cumming, José Guillermo Guerra, Luis Galdames, Domingo Amunátegui Solar, Antonio Huneeus Gana, Gabriel Amunátegui Solar, Eugenio Pereira Salas, Ricardo Donoso, Julio Heise González y Sergio Villalobos. Rescatable fue su interés en la instauración de un sistema de libertades y el compromiso político de varios de los autores mencionados. Si en su paso por el poder hubo una coherencia entre la prédica y la práctica, es para estos efectos intrascendente ${ }^{51}$.

A lo largo del siglo XX surgió una visión contestataria de la anterior, denominada conservadora, que reivindica la herencia cultural indiana, relativiza la influencia francesa y norteamericana, rescata la figura de Diego Portales, considerando que la constitución de 1833 dio a Chile orden, estabilidad y progreso, diferenciándolo de la mayoría de las nuevas naciones. Prescindió de categorías actuales a fin de entrar a entender la mentalidad de la gente del siglo XIX, especialmente de la primera mitad. En lugar de juzgar el pasado, trató de entenderlo. Su visión tiende a ser de

${ }^{48}$ Solo a modo de ejemplo, véase Valencia Avaria, Luis (1986) Anales de la República: textos constitucionales de Chile y registro de los ciudadanos que han integrado los poderes ejecutivo yy legislativo desde 1810 (Santiago, Editorial Andrés Bello, 1986) 2 v.

${ }^{49}$ No es el momento de estudiar los matices entre los autores de cada una de esas corrientes. Entre ellos hay matices y puntos de vista divergentes. Por tratarse esta solamente de una mención del estado de la cuestión, no entraremos a analizar las diferencias existentes entre ellos.

${ }^{50}$ Esa concepción es particularmente relevante en el caso de Donoso, Ricardo, Las ideas políticas en Chile (México, Fondo de Cultura Económica, 1946).

${ }^{51} \mathrm{Al}$ menos en el caso de Domingo Santa María parece haber consenso en que su forma de detentar el poder como presidente tuvo poco de democrática y dialogante. Al respecto, véase Campos, Fernando, Historia constitucional de Chile (Santiago, Editorial Jurídica de Chile, 1956), p. 335. 
largo plazo. Ha dado polifonía a la historia constitucional en Chile ${ }^{52}$. Entre sus exponentes se puede citar a Alberto Edwards Vives, Jaime Eyzaguirre, Fernando Campos, Sergio Martínez, Javier González, Néstor Meza y Mario Góngora. La escuela conservadora ${ }^{53}$ hizo un importante trabajo a lo largo del siglo XX. Se caracterizó por la propuesta de esquemas conceptuales y de trabajo, como los dos primeros profesores citados o por detalladas investigaciones de archivo, que reconstruyeron la realidad jurídica e institucional mediante un análisis caso a caso, como Sergio Martínez ${ }^{54}$, Néstor Meza ${ }^{55}$ y Javier González.

\section{La configuración de la historia constitucional en Chile \\ a) criterio de selección de las obras a analizar}

Por un tema de extensión, resulta imposible analizar las obras de cada uno de los autores arriba citados. Por lo mismo se ha hecho una selección fundada en los siguientes criterios: cuáles fueron las primeras obras escritas en esta disciplina a partir de la promulgación de la constitución de 1833 hasta 1860. En el caso de

${ }^{52}$ Muestra de la vitalidad de esta corriente es el libro El verdadero rostro de Portales, de varios autores, en el que los profesores Bernardino Bravo Lira y Sergio Carrasco Delgado, desde una óptica jurídica, exhiben la formación jurídica de Diego Portales, de marcado carácter indiano, su relación con Andrés Bello, su opinión sobre diversos aspectos del acontecer nacional y su visión acerca de cómo debía configurarse la naciente república. Los citados profesores se hacen cargo de la abundantísima literatura acerca del personaje en cuestión, las causas de la discordia que hasta hoy genera su figura y el aporte que hizo a la evolución institucional chilena, acunando el concepto de República ilustrada.

${ }^{53}$ No compartimos esta denominación. Los historiadores y juristas citados en ningún momento ponen en tela de juicio el proceso de emancipación política y la instauración de las constituciones. Lo que hacen es simplemente matizar posturas y recrear el ideario político y jurídico de esa época. Mientras la tendencia liberal se centra en los textos constitucionales, este grupo ha puesto su acento en el imaginario jurídico, el acervo cultural de la clase dirigente y en lo jurídico, aunque de manera muy tímida, plantean dudas sobre el proceso de cambio de sistema jurídico. Estas dudas dicen relación con el simple hecho de que el derecho europeo vigente en América al momento de iniciarse el proceso emancipador contaba con una serie de principios que no distan tanto de los nuevos valores que habría traído el constitucionalismo norteamericano y europeo, como el principio de la juridicidad y el de sometimiento de los gobernantes al derecho.

${ }^{54}$ De eco entre los entendidos en el momento gaditano y la emancipación política de la América indiana es la obra de Martínez Baeza acerca de la pervivencia del juicio de residencia en el derecho patrio, pues representa una de las primeras investigaciones acerca de la pervivencia de un sistema jurídico - en este caso el derecho indiano- en otro a partir de una institución específica. Martínez, Sergio, La residencia en el derecho patrio chileno, en Revista Chilena de Historia del Derecho, 4 (1965), pp. 129-207.

55 Este autor destacó por reconstruir todas las vicisitudes del período inmediatamente anterior a la primera junta de gobierno, mostrando las diversas maneras en que el derecho indiano encauzaba la participación política. Los mecanismos de participación política descritos por Meza Villalobos guardan cierta concomitancia con la idea de constitución a lo largo de distintos períodos que propone Fioravanti. MezA, Néstor, La actividad politica en el reino de Chile (1806-1810) (Santiago, Instituto de Investigaciones Histórico-Culturales, Facultad de Filosofía y Educación, Universidad de Chile, 1956); Él mismo, Conciencia política chilena durante la monarquía (Santiago, Instituto de Investigaciones Histórico-Culturales, Facultad de Filosofía y Educación, Universidad de Chile, 1958). 
Lastarria se escogieron tres obras que se corresponden con sus objetivos políticos e ideológicos, en los que hay un permanente recurso a la historia. Desde ese punto las obras escogidas son aquellas que poseen un carácter preferentemente jurídico y que abarcan la historia constitucional en el largo tiempo. Por ende, se han excluído aquellas monografías que tratan un corto período o aquellas cuyo objeto es la historia política. En aras de poder analizar si la propuesta de Fioravanti y Marquardt se condice con el desarrollo de la historia del derecho en Chile se han considerado tres iushistoriadores de la escuela chilena de historiadores del derecho y un cuarto que no comparte el enfoque de la escuela recien mencionada.

Para el final han quedado tres autores que, debido al carácter omnicomprensivo de sus obras, al hecho de ser libros que han trabajado con una perspectiva de largo plazo y al claque que han tenido en cuanto docentes universitarios, han sido llamados los clásicos. Reciben esa denominación también por ser los mejores exponentes de cada manera de entender la historia constitucional.

\section{b) el camino hacia una configuración cientifica}

El temprano surgimiento de la historia constitucional se explica, en parte, por necesidades políticas. La guerra de la Independencia dividió familias, ciudades, cortó lazos de amistad ${ }^{56}$. Vastos sectores de la población abrigaban sentimientos de simpatía hacia el monarca. De ahí que apenas comenzó el movimiento juntista no solo surgieron crónicas y memorias sino también ensayos constitucionales. La historia constitucional tardó poco en llegar, pues bastó que la Constitución de 1833 alcanzase los tres lustros de vigencia para que la primera obra de esta disciplina viera la luz. Tal honor correspondió a la Memoria histórico-crítica del derecho público chileno, desde 1810 hasta nuestros días, presentada en la Universidad de Chile en octubre de 1849 por Ramón Briseño ${ }^{57}$.

Dicha obra contiene una recopilación de todas las cartas que llevaron el nombre de constitución y una relación de los hitos más importantes de la historia constitucional chilena, tanto a nivel de textos como de discusiones hasta fines de la década de 1820. Es la obra que sienta las bases del derecho constitucional en cuanto patrio. Describe el proceso de formación de cada uno de los textos y proyectos, los compara y trata de justificarlos como los mejores para las circunstancias que vivía en ese momento el país. Tiene una visión complaciente respecto a la constitución de 1833. Su fuente más importante es la experiencia. Se podría decir que legitima la herencia indiana y la concentración del poder en muy pocas manos. Es una obra de corte tradicionalista.

${ }^{56}$ Este punto ha sido hasta el día de hoy poco estudiado por la historiografía. Solamente a modo de ejemplo, para observar la otra cara del proceso de emancipación, véase URREJOLA, Eduardo, Los Urrejola de Concepción. Vascos, realistas y emprendedores (Santiago, Centro de Estudios Bicentenario, 2010). Existe un comentario de Cartes Montory, Armando en Cuadernos de Historia, 34 (2011), pp. 163-166.

${ }^{57}$ Briceño, Ramón, Memoria histórico-critica del derecho público chileno desde 1840 hasta nuestros días. Obra presentada a la Universidad de Chile en la sesión solemne del 14 de octubre de 1849, con la que celebró el sexto aniversario de su instalación (Santiago, Imprenta de Julio Belin y compañía, 1849). 
A esa obra siguieron las de José Victorino Lastarria, Investigaciones sobre la influencia social de la conquista y del sistema colonial de los españoles en Chile ${ }^{58} \mathrm{de} 1844$, y la Historia constitucional del medio siglo ${ }^{59}$, de 1853. Ambas poseen un carácter muchísimo más crítico del orden existente. Lastarria no estaba conforme con la Constitución de 1833 ni con el sistema político nacido a su alero. En ambas obras se observa un desprecio por lo existente y por lo que es Chile en ese momento. Los libros de Lastarria, aunque escasos en citas, muestran cuán vastos eran los conocimientos del autor acerca de la realidad constitucional en otras latitudes. $\mathrm{Su}$ pluma de escritor y político supera la asepsia propia del académico y del profesor universitario, dándole al constitucionalismo un carácter épico y valorativo del que la obra de Briseño carece. En la primera de ellas, Lastarria hace una acerba crítica del legado español en América y en Chile, haciendo hincapié en las peculiaridades de la conquista, realzando la figura del mapuche y haciendo una fuerte crítica al sistema denominado Constitución histórica o protoconstitucionalismo anterior al siglo XIX. Pone de relieve que el derecho indiano no sería un derecho heredero de la tradición foral medieval sino un producto del absolutismo de Carlos $\mathrm{I}^{60}$. En esta obra Lastarria busca sentar las bases de un proyecto constitucional que rompa todas las ataduras con el sistema indiano. Intenta legitimar el constitucionalismo en el Estado nacional. Para él, el proyecto independentista es de corte republicano constitucional.

La segunda obra citada desarrolla el concepto de constitución y del constitucionalismo; recurriendo insistentemente al derecho comparado, a la historia y a la filosofía. En ella entronca el constitucionalismo con los principios y valores de los movimientos liberales y nacionales de Europa y América, estudia la situación existente en otras regiones de la América hispana. Se hace parte de la discusión acerca de la mayor o menor conveniencia de una monarquía o una república. Tiene el mérito indiscutido de ser la obra constitucional emanada de un publicista chileno que toma partido en esa discusión. Ningún otro autor abrigará abiertamente las pretensiones de fama y reconocimiento internacionales que tuvo Lastarria en su Historia constitucional del Medio Siglo.

Una tercera obra del mentado literato para estos efectos importante es Lecciones de política positiva ${ }^{61}$. Haciendo gala de una mayor moderación a la hora de emitir juicios de valor, Lastarria sienta las bases de cómo, en su opinión, debe entenderse el derecho constitucional que se corresponda con los principios e ideas en boga

${ }^{58}$ Lastarria, José Victorino, Investigaciones sobre la influencia social de la conquista y el sistema colonial de los españoles en Chile (Santiago, Anales de la Universidad de Chile, 1844).

${ }^{59}$ Lastarria, José Victorino, Historia constitucional del Medio Siglo: revista de los progresos de los sistemas representativos en Europa i América durante los primeros cincuenta años del siglo XIX: primera parte de 1800 a 1825 (Valparaíso, Imprenta El Mercurio, 1853).

${ }^{60}$ En esta crítica Lastarria no tuvo una perspectiva histórica adecuada. El período colonial duró casi tres centurias, en las que las instituciones evolucionaron. La primera mitad del siglo XVI estará marcada por el dualismo, a veces transformado en dicotomía municipio-rey, siendo el cabildo la institución a través de la cual los peninsulares efectuarán sus reivindicaciones y participaran activamente en la política de los nuevos reinos.

${ }^{61}$ Lastarria, José Victorino, Lecciones de politica positiva profesadas en la Academia de Bellas Letras (Santiago, Imprenta de El Ferrocarril, 1874). 
en la segunda mitad del siglo XIX. Es un libro con un importante contenido doctrinario, que toma posición frente a los planteamientos de filósofos ilustrados como Rousseau y crítica los distintos modelos que ha desarrollado el derecho constitucional en Europa y Estados Unidos. Este libro muestra a un Lastarria más maduro y reflexivo, más cuidadoso al momento de emitir sus opiniones y algo más prolijo al momento de citar a otros autores. Esta obra tiene un fuerte componente filosófico, recoge parte de las ideas de Comte y formula una idea propia sobre la relación entre derecho y libertad ${ }^{62}$. Su carácter es muchísimo más propositivo y orientado a las discusiones de ese momento. Es así como intenta fundamentar el Estado laico ${ }^{63}$, precisar qué se debe entender por libertad de enseñanza ${ }^{64}$ y sentar las bases del federalismo ${ }^{65}$. Las Lecciones constituyen, muy probablemente, dentro de la abundante producción de Lastarria, el libro mejor logrado y más propositivo. Combina principios e ideas matrices de la doctrina constitucional y la filosofía jurídica en boga en el siglo XIX con el ordenamiento constitucional en ese momento vigente.

Lastarria buscaba por medio de estos estudios y de la enseñanza reformar la sociedad y el sistema político y constitucional. Como ya se dijo, su producción historiográfica dista de ser rigurosa ${ }^{66}$. Pero su torcido manejo no le resta el valor de suplir el vacío hasta ese momento existente en cuanto a una filosofía que inspirase las normas constitucionales. Dicha discusión había sido preferentemente legislativa y en casos puntuales. Él intentó proyectar una visión del mundo en las abstractas normas de la Constitución. Su objetivo era deslegitimar la de 1833 y su sistema político por haber recogido múltiples elementos de la tradición indiana, que en su opinión era una cultura carente de ideas de participación política y libertad. Para alcanzar dicho fin se propuso demostrar que la herencia indiana en ningún caso era heredera de la tradición libertaria de la España del medioevo y que el derecho indiano tampoco representaba tan apreciados valores como la tolerancia religiosa, la libertad y la igualdad: "En las repúblicas aun predominan en la vida social las ideas teológicas y metafísicas de la civilización de la edad media, y en Chile, más que en ninguna otra parte, han logrado ellas reconstituirse en un cuerpo completo de instituciones [... ${ }^{167}$. En otras palabras, Lastarria aterrizó a Chile la leyenda negra antiespañola. Fue un trabajo de carácter netamente ideológico. En palabras de Luis Oyarzún, "con Lastarria aparece por primera vez nitidamente formulada la idea de que la república requería imperiosamente para su plena realización el empleo de una doctrina sobre el hombre y la sociedad que pudiera servir de guía a la política de las nuevas generaciones" ${ }^{6}$.

Dichos esfuerzos tuvieron un correlato para el período inmediatamente ante-

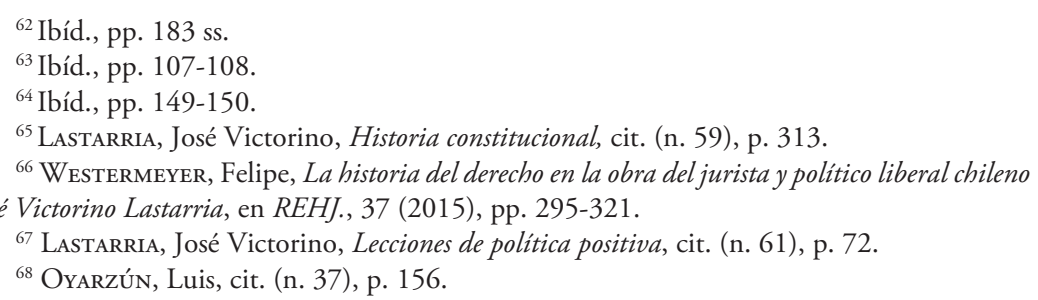


rior a 1833 en la obra de Federico Errázuriz Zañartu, Chile bajo el imperio de la Constitución de $1828^{69}$. Él intentó, por medio de la crónica de la guerra civil de los años 1829-1830, deslegitimar la Constitución de 1833 y el proyecto político pelucón. Mediante la relación de una serie de incidentes y episodios que marcaron ese conflicto fraticida, pone de relieve la bajeza moral de una de las facciones involucradas; su poco respeto por la voluntad soberana; la insubordinación de parte de los mandos militares al poder civil y la intolerancia religiosa de los vencedores. Plantea que el régimen político fundado por estos era de carácter contramayoritario, basado en el orden y la tradición y con escaso acento en las libertades y los derechos individuales. En resumen, Errázuriz Zañartu realzó, en lo estrictamente constitucional, la necesidad de introducir cambios en el sistema constitucional vigente en Chile. En lo político, trató de fundamentar la superioridad moral de su sector, criticando que la carta fundamental vigente se basaba en miedos y prejuicios. Errázuriz y Lastarria usan la historia como medio para legitimar otros proyectos políticos y constitucionales. Sistematizan y reconstruyen las discusiones jurídicas y políticas, llevando la historia al debate jurídico.

Un paso más adelante fue Manuel Carrasco Albano en su libro Comentarios sobre la Constitución Politica de $1833^{70}$. Superó el enfoque histórico y doctrinario, entroncando ambos aspectos del derecho constitucional con el texto vigente. Por medio de un análisis exegético busca desentrañar el sentido y alcance de cada uno de los artículos de la carta fundamental citada. Para ello comenta el texto recurriendo a los elementos gramatical, histórico y lógico de interpretación jurídica. Su crítica a la constitución es menos ácida y mejor fundamentada que la de Lastarria. Parte del hecho insoslayable, de que casi 20 años de vigencia y aplicación hacen de ese texto una realidad. Por esa razón trata de valorarla en su justa medida. La Constitución de 1833 no es un texto perverso en sí mismo. Hay disposiciones de enorme valor dogmático y otras que no se ajustan a lo que debía ser una carta fundamental que siguiese los lineamientos del constitucionalismo decimonónico. Su principal crítica a esta carta es su carácter poco democrático y su débil acento en la igualdad. En su opinión, estaba a la vanguardia en la protección de los derechos civiles; no así de los derechos políticos. En base a esas dos falencias propone una expansión del derecho a voto mediante una flexibilización de los requisitos para obtener la calidad de ciudadano. A fin de construir una sociedad más plural y atraer mano de obra extranjera propone, por una parte, la consagración de la libertad religiosa y de cultos y, por otra, menores requisitos para acceder a la nacionalidad. Fundamenta la igualdad en el cristianismo; pues dicho credo plantea la igualdad de todos los seres humanos ante Dios. El otro fundamento filosófico al que recurre es el derecho natural racionalista. Para defender su propuesta de libertad de cultos menciona la situación de Alemania, en la que, habiendo un pueblo religioso, existe en las universidades tal libertad de

\footnotetext{
${ }^{69}$ Errázuriz, Federico, Chile bajo el imperio de la Constitución de 1828. Memoria histórica que debió ser leída en la sesión solemne que la Universidad de Chile hubo de celebrar en 1860 (Santiago de Chile. Imprenta Chilena, 1861).

${ }^{70}$ Carrasco, Manuel, Comentarios a la Constitución de 1833 (Valparaíso, Imprenta y Librería El Mercurio, 1858).
} 
expresión que hay profesores de teología que han sido capaces de poner en duda la imagen que en ese momento existía acerca de la Divinidad.

La obra de Manuel Carrasco fue un aporte valioso pues no solo sistematiza el texto sino que además le dio otro alcance a los derechos políticos y a la democracia. Propuso una interpretación compatible con la dinámica social de ese entonces, marcada por la inmigración europea hacia América y por el paulatino avance de la revolución industrial, proceso al que Chile debía subirse, con la consiguiente política estatal de fomento fabril y la importación y formación de mano de obra calificada. Interpreta las normas de la Carta de 1833 de acuerdo a los parámetros vigentes en Europa. En el derecho constitucional hay autores con vocación de polítólogos y otros que son artistas del derecho, los que proponen reformas e interpretaciones que compatibilizan la norma con nuevas necesidades. Es inconcuso a qué grupo pertenece Carrasco Albano.

Sobre Domingo Santa María ${ }^{71}$, Isidoro Errázuriz ${ }^{72}$ y Benjamín Vicuña Mackenna, atendida la vastedad de su producción histórica y jurídica y los estrechos límites de este artículo, resulta imposible dedicarles los párrafos que se merecen. Baste decir, para efectos de este artículo, que comparten gran parte de las características de los últimos dos autores en estudio. Como último comentario acerca de los representantes de la corriente liberal, importante es indicar que, dada la cercanía generacional que tenían con el período que media entre 1810 y 1833 , la distinción entre derecho histórico y derecho vigente y su uso de la historia no siempre es clara.

Con ocasión del primer centenario de la primera junta de gobierno, vio a la luz la obra de Antonio Huneeus Gana, La Constitución de 1833. Ensayo sobre nuestra historia constitucional de un siglo ${ }^{73}$. Ella resalta, por una parte, la figura de Diego Portales y, por otra, valora los planteamientos foráneos. Es una obra de carácter eminentemente jurídico en que hay breves explicaciones de las instituciones reguladas por la carta fundamental de 1833, alusiones a los principales derechos y un estudio de cómo evolucionó la relación entre los poderes del estado al alero de la en ese momento casi octogenaria constitución. El autor hace un fino análisis jurídico hasta 1891. Desde ese hito su análisis está mucho más marcado por la realidad política y social de Chile. Si bien su diagnóstico no es alarmista, esta obra podría ser catalogada como la versión jurídica e institucional de la crisis del centenario. Muestra la discordancia entre los objetivos de las reformas constitucionales que consolidaron el parlamentarismo y sus resultados efectivos. Crítica las prácticas clientelistas y la cooptación de la burocracia estatal por parte de los partidos políticos, la falta de objetivos de carácter nacional, el despilfarro de recursos públicos, la política económica basada en las rentas del salitre con escaso

\footnotetext{
${ }^{71}$ Santa María, Domingo, Vida de don José Miguel Infante (Santiago, Imprenta Chilena, 1853).

${ }^{72}$ Errázuriz, Isidoro, Historia de la administración Errázuriz (Valparaíso, Imprenta La Patria, 1877).

${ }^{73}$ Hunneus, Antonio, La Constitución de 1833. Ensayo sobre nuestra historia constitucional de un siglo. Publicado en la Revista Chilena de Historia y Geografia. Estudios Chilenos. Corregido (Santiago, Editorial Splendid, 1933).
} 
fomento de otras actividades y la ausencia de políticas industrializadoras ${ }^{74}$. En la parte final de esa obra, Huneeus usó la historia constitucional como pretexto para denunciar vicios y falencias institucionales, la irresponsabilidad de la clase dirigente y la poca adaptación del sistema político a los nuevos tiempos y procesos sociales.

Las décadas posteriores a la obra de Huneeus estarán marcadas por la discusión política que derivará en una nueva constitución y el afianzamiento del sistema presidencial y por el surgimiento de la historia del derecho como disciplina jurídica de carácter holístico, lo que obligó a la historia constitucional a entrar en asuntos metodológicos. En esa nueva discusión tomaron parte dos autores: Julio Heise y Jaime Eyzaguirre. El primero de ellos definió la historia constitucional como una rama de las ciencias del derecho, perteneciente al derecho público, cuyo objeto son los esfuerzos realizados para dar forma material a los postulados filosóficos que generan la organización política de un país. De ese modo, Heise incluye instituciones públicas, evolución de las garantías individuales en fin "todas las fuerzas históricas que determinan la trayectoria del hecho constitucional [...] el conjunto de hechos y doctrinas que influyen en la creación de textos constitucionales" o como él mismo resumió "la historia constitucional es una exposición sistematizada de todas las fuerzas históricas que han influido en el desenvolvimiento del derecho público chileno"75. En sus obras posteriores ${ }^{76}$ acota esa extensa definición. Su tesis sustenta que a partir de 1810 el devenir institucional estuvo marcado por un largo y exitoso proceso de adaptación de los ideales constitucionales norteamericano y francés en Chile.

El segundo autor, en su Historia constitucional de Chile, también intenta fijar un objeto de estudio. Aunque no siempre lo delimita bien, tiene el mérito de ampliar el objeto de estudio a "las instituciones políticas y sociales y a hechos no jurídicos que influyen de manera decisiva en las fuentes legales" 77 . Por ende, no aparece con claridad cuál es la diferencia entre la historia constitucional y la historia del derecho. Asimismo, no presta especial atención a los modelos francés y norteamericano. Tiene el mérito de abarcar no solo las principales reformas constitucionales y sino también las leyes que zanjaron las principales discusiones constitucionales, como por ejemplo las cuestiones teológicas o la larga discusión entre parlamentarismo y presidencialismo. Si bien su definición de historia constitucional es más reducida que la de Heise, abarca también la herencia indiana, escasamente considerada por su contemporáneo.

Mención aparte merece la Escuela Chilena de Historiadores del Derecho ${ }^{78}$

${ }^{74}$ Ibíd., pp. 106 ss.

${ }^{75}$ Heise, Julio, Historia constitucional de Chile ${ }^{2}$ (1950, Santiago, Editorial Jurídica de Chile, 1954), p. 7.

${ }^{76}$ Heise, Julio, Años de formación y aprendizaje político: 1810-1833 (Santiago, Editorial Universitaria, 1978); ÉL MISMO, 150 años de evolución institucional ${ }^{6}$ (1960, Santiago. Editorial Andrés Bello, 1989).

77 Eyzaguirre, Jaime, cit. (n. 3), p. I.

${ }^{78}$ Para los fines de este artículo, es importante entrar a dar algunas características de este grupo de académicos, que marcan una diferencia con los cultores de la historiografía constitucional. Se trata de un grupo de juristas chilenos que ha estudiado los temas jurídicos en una perspectiva histórica. Se caracteriza por un análisis en el largo plazo, abarcando los derechos romano, 
que, buscando la pervivencia de un sistema jurídico en otro, ha llegado por esta última vía al estudio del derecho constitucional y al derecho decimonónico de manera relativamente reciente. Sus investigaciones abarcan temas de relevancia continental, generando esquemas de trabajo útiles a los cultores de la disciplina, centrados en la realidad americana. Han tomado el aparataje conceptual de las tradiciones iushistoriográficas del viejo continente y las han adaptado al mundo americano. Por tal razón, sus trabajos son los que, probablemente sin intención, se hacen cargo del diagnóstico que a nivel global han formulado Fioravantti y Marquardt. Han ampliado las fuentes a consultar y tratado de reconstruir el desarrollo dogmático de las instituciones constitucionales. Dentro de ellos destacan los estudios efectuados por Bernardino Bravo Lira y Antonio Dougnac Rodríguez. El primero propone un esquema conceptual en el plano de las ideas, mediante un análisis que abarque desde el nacimiento de los reinos en América hasta nuestros días. Con un frecuente uso del recurso a la comparación entre distintas regiones del orbe, el profesor Bravo Lira sostiene que el orden constitucional en Iberoamérica se da en la medida en que las constituciones escritas se ajusten a la constitución histórica ${ }^{79}$.

canónico, indiano y patrio. estudiando desde Chile y la América hispana la evolución jurídica, tanto desde un punto nacional como continental, sin dejar de lado el recurso comparativo y haciendo un uso de fuentes en el amplio sentido de la palabra. Entre sus miembros fundadores se cuentan personas de distintas procedencias como Jaime Eyzaguirre, Alamiro de Ávila y Manuel Salvat Monguillot. La riqueza de este grupo es la variedad de sus acentos, contando entre ellos comparatistas, romanistas, publicistas, y antropólogos jurídicos. Un rasgo que hasta ahora los ha identificado es el cultivo simultáneo del derecho romano y la historia del derecho. Cada uno de ellos ha estudiado el fenómeno histórico jurídico desde una perspectiva propia. Entre sus actuales representantes cuentan Alejandro Guzmán Brito, Bernardino Bravo Lira, Antonio Dougnac Rodríguez, Sergio Martínez Baeza, Carlos Salinas Araneda y, de una nueva generación, Javier Barrientos Grandón, actualmente residente en España. Para una mayor ilustración acerca de este grupo véase Dougnac, Antonio; Vicencio, Felipe, La Escuela Chilena de Historiadores del Derecho y los estudios jurídicos en Chile (Santiago, Facultad de Ciencias Jurídicas y Sociales de la Universidad Central, 1999-2000) 2 vols. Hay una interesante reseña de Bravo, Bernardino, en Revista Chilena de Derecho, 27/1 (2000), pp. 621-624.

${ }^{79}$ En este punto es importante realizar algunas aclaraciones conceptuales, aun a riesgo de explayarse en demasía en una nota a pie de página. La idea de constitución histórica ha sido usada por diversos historiadores pero no siempre con el mismo significado. El profesor Bravo da a este concepto un carácter dinámico y progresivo. Su construcción conceptual es completamente distinta a la que formuló Jovellanos en el siglo XVIII. Importante es tener presente que en las Cortes de Cádiz casi ningún diputado americano recurrió a este concepto, por encontrar sus raíces en la legislación hispana previa al siglo XVI. Muy pocos juristas pensaron en una constitución histórica de las Indias. Lo último junto al carácter de progresivo y dinámico hace que el concepto de Bernardino Bravo dé un significado distinto del concepto c o n s t i t u c i ó n h i s t ó r i c a. Bravo destaca que la constitución histórica en las Indias está marcada por su fuerte impronta estatal, con una decena de nuevos Estados en el nuevo continente en 1609, cada uno de ellos con orígenes, instituciones y trayectorias propias. La base de estos Estados fue la jurisdicción: "proteger al más débil y mantener a los vasallos en paz y justicia", el carácter evangelizador y una marcada pluralidad de poderes. La jurisdicción se basó al principio en la contraposición ciudad versus corona o mejor dicho, cabildo versus monarca; pero ese eje dual duró poco pues impedía hacerse cargo del mundo aborigen, por lo que pronto surgieron las audiencias, como medio para perseguir y castigar los abusos, pasando del recién citado eje a la 
Esta última surgió en el derecho indiano y sobrevive por medio de las instituciones que nacieron o se enraizaron en dicha época, tales como el tribunal de cuentas, la judicatura, el presidente de la República, la universidad y la Iglesia católica. El mentado profesor destaca la fortaleza de la primera institucionalidad indiana en América frente a un orden constitucional de carácter feble, lo que se manifestaría en la corta vigencia de la mayor parte de las constituciones escritas desde 1810 a la fecha. Su aproximación constata la divergencia entre lo que planteaban las nuevas élites surgidas en el siglo XIX y las idiosincrasias jurídicas locales. El académico destaca aparte de la mentada fortaleza institucional, el alto nivel de legitimidad de las instituciones indianas frente a las constituciones y la enorme flexibilidad de la constitución jurisdiccional para adaptarse a realidades cambiantes. Provocativo es su análisis respecto al sistema de valores del derecho indiano y su pervivencia durante las dos últimas centurias. Igual lo es el contraste que hace entre este y el sistema de valores que trae el constitucionalismo. Mediante la comparación de la realidad vigente hasta fines del siglo XVIII y la posterior implementación del sistema constitucional matiza el discurso acerca de las mejoras que habría traído el constitucionalismo a la realidad hispanoamericana ${ }^{80}$.

Bravo se hace cargo de una nueva realidad político y social, la que trae el nuevo orden liberal, que no logra satisfacer a las mayorías, por lo que rechaza la dos veces centenaria tesis del aprendizaje político. Considera que doscientos años es mucho tiempo para continuar cometiendo los mismos errores ${ }^{81}$. Resume la realidad y la cultura jurídica iberoamericana en el área del derecho público con el dicho: "las constituciones pasan, las instituciones quedan". Para el caso chileno, Bravo sostiene que la República conservadora (1830-1860), no pasa de

dualidad real audiencia-presidente, o en términos actuales, judicatura-poder ejecutivo y sus cuatro ramos: justicia, gobierno, guerra y hacienda. Las reales audiencias fallaban en derecho, justicia y equidad, con amplias facultades que incluían la posibilidad de anular los actos de gobierno. El gobernador o virrey, según el reino del que se tratase, poseía amplias facultades ejecutivas y militares. El orden indiano se orientaba por los principios de protección a las personas por medio de acciones judiciales y la distribución de poder entre los órganos que representaban al monarca, generándose un sistema de frenos y contrapesos entre estos y respecto a una serie de poderes menores, entre los que cuentan la Iglesia, las universidades y los gremios. La base social de ese Estado eran las dos repúblicas: la española y la de indios, cada una con cultura, idiomas, estatutos y derechos distintos. Por ello el profesor Bravo indica que el Estado indiano era multicultural. Esa misma diversidad, unida al fin evangelizador le dio al Estado, antes que, en Europa, el carácter de conformador de un orden social. A lo largo del siglo XVIII pasa a ser un importante factor de gobierno la eficiencia y la modernización, por lo que se creen una serie de nuevas instituciones de carácter administrativo, cuyo núcleo estaba conformado por las intendencias, el ejército y oficinas como la contaduría mayor. Bravo resume la constitución histórica indiana "no como una construcción legal o doctrinal, sino como una compleja trama viva de poderes e instituciones arraigadas en ideales políticos comunes a la población como el servicio a Dios, al rey, a la patria y al buen gobierno. Debido a ese arraigo en la conciencia política, la constitución jurisdiccional tuvo vitalidad propia, capacidad de adaptación a nuevas condiciones que le han permitido vivir y sobrevivir de uno u otro modo hasta nuestros días". La cita en Bravo, Bernardino, Constitución y reconstitución: historia del Estado en Iberoamérica (siglos XVI al XIX) (Santiago, Abeledo Perrot-Legal Publishing), p. 32.

${ }^{80}$ Ibíd., passim.

${ }^{81}$ Ibíd., p. 55. 
ser una versión aggiornata bajo formas republicanas de la monarquía ilustrada dieciochesca, fundamentando esas líneas de continuidad en una serie de aspectos que rebasan el plano estrictamente jurídico ${ }^{82}$. De ahí que, como ya se citó, Bravo ha sentado en la historiografía constitucional chilena el concepto de República ilustrada, superando, en base al concepto de ilustración católica, la idea de la república católica ${ }^{83}$.

También con una visión de largo plazo pero centrada en la evolución detallada de las instituciones el indianista Antonio Dougnac, en un muy citado artículo ${ }^{84}$ analiza en la letra de los textos constitucionales de la Patria Vieja el uso de la terminología y la institucionalidad indiana por parte del primer constituyente ${ }^{85}$. Sin lugar a dudas, desde un punto de vista estrictamente jurídico es la obra mejor lograda entre los que manifiestan una postura revisionista del constitucionalismo y el derecho patrio. Su artículo coincide con otros que de manera coetánea e independiente han desarrollado en otras partes de Iberoamérica y España autores como Alí López ${ }^{86}$, Marta Lorente y Carlos Garriga ${ }^{87}$. Por medio de un análisis

${ }^{82}$ Bravo, Bernardino, Una historia jamás contada. Chile 1811-2011. Cómo salió dos veces adelante (Santiago, Ediciones Origo, 2016).

${ }^{83}$ Bravo, Bernardino, Constitución y reconstitución, cit. (n. 79), p. 43.

${ }^{84}$ Dougnac, Antonio, El sistema jurídico indiano en el constitucionalismo chileno durante la patria vieja (1810-1814), en REHJ., 22 (2000), pp. 225-266.

${ }^{85}$ Es un poco precipitado sostener en base a ese artículo la discrepancia que algunos parecen ver entre las posturas sostenidas por el profesor Bravo Lira y el profesor Dougnac Rodríguez. La historia del derecho consta siempre de un análisis de la norma y otro de historia de las ideas. Cómo se implementan las ideas jurídicas en un ordenamiento jurídico obedece a un estadio de desarrollo posterior. El hecho que se haga un análisis de la pervivencia de la mentalidad y de la terminología indiana en los textos constitucionales del período 1810-1814 no importa automáticamente reconocer el valor del constitucionalismo en la mentalidad de esa época. A nuestro modesto entender, ver tales discrepancias implica comprender el derecho constitucional, solo por medio de la constitución escrita. Dicha aseveración, como ya se ha visto más arriba, no genera conceso entre los ius historiadores, pues la constitución ha sido interpretada tanto como una manifestación de la forma en que cada época limita el poder de los gobernantes así como también como una expresión del constitucionalismo y de la ilustración. Dicha manera de comprender el concepto de constitución también es criticable a nivel de derecho comparado. Basta ver los casos de Inglaterra y Hungría. Más bien lo que ambos autores ponen de manifiesto es el proceso de transformación de un sistema jurídico y sus consecuencias. Ambos estudian diferentes facetas de un fenómeno multifacético, sujeto a los vaivenes y requerimientos de la vida real, el primero a nivel político e institucional y el segundo en la letra de los textos. Por ende, resulta un tanto peregrino deducir tesis y visiones contrapuestas con tan poco material. La historia del derecho recién ha entrado a trabajar este proceso de transformaciones y existen aún una serie de instituciones y aspectos que permanecen en un claroscuro, como por ejemplo la efectiva jerarquía de las normas y cómo ese proceso de transformación fue sopesado por los distintos actores jurídicos. No negamos la posible validez de la tesis de la contraposición de visiones entre ambos profesores, pero la disciplina histórico-jurídica requiere de un mayor desarrollo para poder aventurar de manera tan tajante esas diferencias, en especial respecto al siglo XIX, que todavía en Chile constituye una materia en gran parte desconocida.

${ }^{86}$ López, Alí, La real audiencia de Caracas (Mérida, Ediciones del Rectorado de la Universidad de los Andes, 1998).

${ }^{87}$ Probablemente la obra de los dos últimos profesores, Cádiz, 1812: La Constitución jurisdiccional, constituye el punto de partida de una nueva forma de entender el constitucionalismo 
puntilloso y literal el profesor Dougnac demuestra la pervivencia de la cultura indiana en el nuevo sistema. El citado académico ha desarrollado en trabajos posteriores, de manera sistemática aunque indirecta, la pervivencia del derecho indiano en el patrio y la manera en que las prácticas, usos y mentalidad indiana modelaron el devenir constitucional en Chile o, desde otra perspectiva, cómo la norma indiana fue interpretada para dar lugar a la institucionalidad y al derecho patrio $^{88}$. Un tercer miembro de esta escuela, el profesor Javier Barrientos Grandón, ha puesto el acento en la no reconocida influencia de la constitución de Cádiz en todas las constituciones posteriores a la de 1818 . Su propuesta incorpora al constitucionalismo chileno en la familia jurídica gaditana ${ }^{89}$. Pese a tales avances, este grupo no ha presentado aún tratados de historia constitucional.

Por ello, para dimensionar el estado y los logros de la disciplina, es imprescindible remitirse a los t r e s c lá s i c o s : el primero por la exhaustiva descripción dogmática, el segundo por darle a las normas constitucionales una asidero histórico que se engarza con la historia de Chile casi desde el mismo momento de la conquista, y el tercero por problematizar una serie de aspectos muchas veces preteridos, en el marco de hacer de la Constitución un texto vivo. Las obras mejor logradas, de consulta obligada para cualquiera que se adentre en esta disciplina, son: Evolución constitucional de Chile 1810-1925, de Luis Galdames; Historia constitucional de Chile ${ }^{90}$, de Fernando Campos Harriet, y Génesis y vigencia de los textos constitucionales chilenos, de Sergio Carrasco Delgado ${ }^{91}$.

Los tres autores buscan recrear la realidad política de cada momento sin abandonar la dimensión jurídica de cada uno de los textos constitucionales. Comparten el mérito de la meticulosidad, el análisis pormenorizado de cada una de las fuentes, las referencias a los principales cultores del derecho público y una adecuada ponderación de la historia. Son obras eminentemente jurídicas que no pierden de vista el contexto histórico. No son ni recopilaciones acríticas ni tratados que olvidan qué su objeto de estudio son los textos fundamentales. En un esquema de historias constitucionales de carácter nacional, son obras que están en la cúspide. Las tres son críticas en cuanto denuncian las falencias de cada carta fundamental y cómo pudieron haber entorpecido o facilitado el proceso político. Empleando el método que han utilizado, es muy poco lo nuevo que se puede aportar. Ellos han agotado ese esquema de trabajo.

La obra de Luis Galdames es extensa y detallista, recurre a la historia general sin olvidar que su objeto es la constitucional. Describe bien el juego político

en base a los entronques con el protoconstitucionalismo anterior. Al haber sido la Constitución de Cádiz fuente inspiradora de casi todas las constituciones chilenas en el siglo XIX, a partir de la de 1822, el análisis de los citados juristas cobra también importancia en Chile.

${ }^{88}$ Dougnac, Antonio, Del derecho indiano al patrio: el tránsito del magistrado Juan de Dios Vial del Río (1774-1850), en Revista Chilena de Historia del Derecho, 19 (2003), pp. 63-133.

${ }^{89}$ Barrientos, Javier, La Constitución de Cádiz en Chile, en Escudero, José (ed.), Cortes y Constitución de Cádiz. 200 años (Madrid, Fundación Rafael del Pino, 2011), III, pp. 674-699.

${ }^{90}$ Campos, Fernando, Historia constitucional de Chile (Santiago, Editorial Jurídica de Chile, 1956).

${ }^{91}$ Carrasco, Sergio, Génesis y vigencia de los textos constitucionales chilenos ${ }^{3}$ (1983, Santiago, Editorial Jurídica de Chile, 2002). 
tras cada uno de los textos fundamentales sin descuidar aspectos dogmáticos. Explica el contenido de las normas de cada una de las constituciones acuerdo al contexto cultural y político en el que surgen. Es la obra más extensa que ha dado la disciplina en Chile y material oficial de estudio en liceos y colegios públicos durante la primera mitad del siglo $\mathrm{XX}^{92}$. Obra de innegable valor dogmático y gran divulgación.

Campos Harriet posee un concepto de constitución más amplio. Distingue entre constituciones e instituciones constitucionales, sentando las bases de las últimas en el derecho indiano. Busca dar al derecho constitucional raíces que anteceden por mucho a las constituciones escritas. Asimismo, desarrolla de forma paralela la historia política y la reconstrucción dogmática. En este último punto, con enorme visión, eleva al carácter de fuente de derecho constitucional una serie de leyes que daban forma a instituciones de indiscutible rango constitucional, como por ejemplo la propiedad y la ciudadanía ${ }^{93}$.

Al profesor Sergio Carrasco Delgado, jurista y a la vez especialista en historia política de Chile, corresponde el mérito de recopilar y estudiar la génesis y el tenor literal de todos los textos que, por su contenido, ameritan el calificativo de constitucional, independiente de la denominación que recibieron. Dicho enfoque, en apariencia exegético, no lo lleva a descuidar las circunstancias históricas. Sergio Carrasco es el único autor que hace un esfuerzo serio por ampliar la categoría conceptual textos constit u c i o n a les, sistematizando con excelencia todas las fuentes formales que han llevado a la actual configuración del derecho constitucional chileno. Del mismo modo, el profesor Carrasco enumera a lo largo del libro los hechos políticos y sociales que en su opinión tuvieron una relevancia constitucional, muchos de ellos abordados por la historiografía general y por la política, pero aún no por la constitucional ${ }^{94}$. Esta obra enriquecen el debate con dos puntos de vista no siempre bien abordados por las ciencias jurídicas: el excesivo centralismo político y administrativo existente en Chile y la corta vigencia de muchísimas constituciones. Carrasco usa la historia para explicar ambos fenómenos desde una perspectiva jurídica.

${ }^{92}$ Eduardo Andrades hace hincapié en una nota a pie de página -nota $n^{\circ}$ 9- en este a veces poco ponderado aspecto a la hora de ponderar la influencia de un determinado autor. ANDRADEs, Eduardo, "La incultura en la que España mantenía a sus colonias", Dos tópicos del mito fundacional republicano en Chile, en REHJ., 40 (2018), p. 286.

${ }^{93} \mathrm{El}$ enfoque de Campos ve en las constituciones más que derechos un conjunto de instituciones importantes para la vida en sociedad que vuelven a ser sistematizadas en el texto fundamental. Asi podría decirse que su idea de los derechos políticos o la propiedad es de instituciones.

${ }^{94}$ Centrándose en el período de la Constitución de 1925, Carrasco aborda el rol de las huelgas subversivas y de las matanzas obreras acaecidas en este período para poder dimensionar la real efectividad y validez de las normas constitucionales. Asimismo, repasa el rol de las fuerzas armadas en ese período y cuestiona abiertamente el mito de la obediencia y la sujeción de estas al poder civil. Asimismo, instala el tema de las personalidades de Arturo Alessandri, Carlos Ibáñez y Marmaduke Grove a la hora de analizar el nuevo perfil que adoptaran instituciones como la presidencia de la república. Tales fenómenos, descritos por Carrasco en el período anterior a la década de 1970, relativizan la idea de la estabilidad institucional anterior a esa década. Por medio de ellos plantea dudas con el objeto de hacer de la Constitución un texto efectivamente vivo y aplicable a todos los sectores de la población, no solo a las elites políticas y económicas. 
Probablemente por el desfase temporal y por el estado en que cada uno de los tres autores debió hacerse cargo de la disciplina en cuestión, sus obras no alcanzaron a rescatar la influencia del derecho comparado en todas sus dimensiones ni hacerse cargo de las grandes tendencias doctrinarias del derecho constitucional, ni tampoco incorporar los nuevos planteamientos acá citados. Como ya se dijo, el enfoque de estos tres autores es completamente nacional, explicando, cada uno a su manera, cómo el derecho constitucional llegó hasta el momento en que los sendos libros fueron escritos. Los tres clásicos ponen de relieve el desenvolvimiento político e ideológico, así como los principales hitos de la historia constitucional. Se centran en lo que fue pudiendo no haber sido. Tal vez esa es la explicación a la escasa problematización que los tres clásicos hacen del desarrollo dogmático de los derechos, principios y prácticas institucionales más allá de la clásica disputa entre el presidente de la República y el Congreso Nacional bajo el imperio de la constitución de $1833^{95}$. No obstante estas críticas -es de toda justicia reconocerlo- estos tres autores han dejado una vara altísima. Para efectos de desentrañar la posible existencia de una tradición constitucional estas obras son consulta obligada, pues agotaron una manera de entender la historiografía constitucional.

Por último, de comienzos de esta década es el libro Estado constitucional liberal católico en Chile (1812-1924), del profesor Eric Palma. Dicho autor intenta reformular los esquemas de historia constitucional. Meritorias son sus propuestas de redefinición de conceptos recurrentes en la historia nacional como Patria Vieja, períodos conservador y realista, etc.; sus cuestionamientos a las tipologías liberales así como su intento de incorporar a la historia constitucional otros aspectos poco estudiados del período, preferentemente vinculados a la historia social. Se hace cargo de problematizar y cuestionar las tesis hasta hoy predominantes en la historia constitucional chilena, rebatiendo a la Escuela Chilena de Historiadores del Derecho. Aparte de ello, destaca su interpretación de la Patria Vieja como una época en que el régimen de gobierno fue el de una monarquía constitucional y su adaptación de la tesis del ciudadano feligrés y la ciudadanía católica ${ }^{96}$. Esta novedosa interpretación corre en una dirección distinta a los planteamientos que acá se exhiben, pues concibe la historia del derecho como una disciplina histórica y no jurídica ${ }^{97}$, cuyo objeto de estudio preferente son las interacciones y disputas de poder entre los distintos sectores de la sociedad y no la dogmática. Desafiante es la vinculación que efectúa entre la historia social y los textos constitucionales.

${ }^{5}$ Pienso en especial en la declaración de los derechos del pueblo de Chile del año 1811, en el proyecto constitucional del año 1813 y en el rol del diputado chileno ante las Cortes de Cádiz, Joaquín Fernández de Leiva.

${ }^{96}$ Alonso García, Gregorio, Ciudadanía católica. Identidad, exclusión y conflicto en la experiencia liberal hispana, en Molina Aparicio, Fernando (ed.) Extranjeros en el pasado. Nuevos historiadores de la España contemporánea (Bilbao, Universidad del País Vasco, 2009), pp. 45-72.

${ }^{97}$ Palma, Eric, cit (n. 4), p. 46. 


\section{NuESTRA PROPUESTA}

Del análisis efectuado en las páginas anteriores parece inconcuso que de las críticas formuladas por el profesor Marquardt, al menos las dos primeras son válidas también para Chile. La historia constitucional en Chile tiene un carácter casi exclusivamente nacional y se encuentra muy centrada en los mismos textos constitucionales y sus reformas. Varias obras, con la excepción de los c l á s i c o s , confunden parcialmente la historia constitucional con una historia social, política, económica y electoral del país. Temas como relaciones diplomáticas, tratados de límites y guerras dan también para entender parte de esas obras como una historia del Estado chileno.

Tal problemática atraviesa la historiografía constitucional a nivel global. Las palabras del profesor alemán Christoph Gusy interpretan muy bien el dilema de la historia constitucional: "La historia constitucional está siempre frente al problema de la elección y de los límites del objeto de estudio. Desde la política, la historia social y la económica surge siempre la pregunta, cuando un proceso social adquiere carácter constituyente y desde la historia del derecho surge la pregunta acerca de qué fuentes del derecho tienen el carácter de constitucionales"

Por ese motivo proponemos un nuevo enfoque. La historia constitucional debe, a partir de lo realizado por los tres clásicos, recoger los métodos y propuestas de la historia del derecho, de alguna manera esbozados por los tres miembros de la escuela chilena de historiadores del derecho arriba citados. Pero a fin de diferenciarla de la constitucional es imprescindible recurrir al criterio formal en un sentido amplio. Son materias de la segunda aquellas que hayan sido recogidas en el siglo XIX o posteriormente por el derecho constitucional o por las constituciones. Así como no todo derecho es derecho constitucional, no toda la historiografía jurídica es historiografía constitucional. Hablamos de un criterio formal pues así nos hacemos cargo de un derecho que se encontraba en expansión, pasando de ser una solución de emergencia ante la ausencia de un monarca a la síntesis de principios, libertades y deberes que debían organizar la vida jurídica y política en los nuevos Estados. El criterio formal también recoge el hecho de que desde el siglo XIX, salvo una o dos excepciones en occidente, el derecho constitucional se construyó a partir y para la constitución escrita. Asimismo, ese criterio permite hacerse cargo de la paulatina imposición del positivismo jurídico y la escuela de la exégesis, para los que el tenor literal de la norma era tan importante.

Para estos efectos es oportuno recordar que en materia de historiografía jurídica el siglo XIX sigue siendo muy poco conocido. En el marco del surgimiento del derecho patrio, al derecho constitucional correspondió el honor de ser el primero de adquirir estatus nacional; pero es solo una parte del ordenamiento jurídico. Es difícil investigar y determinar qué fue el derecho constitucional en el amplio sentido de la palabra sin haber claridad acerca de cómo este interactuó con otras disciplinas jurídicas. En la medida en que la historia del derecho se adentre en el todavía ignoto siglo XIX será más fácil hacer historia constitucional y distinguirla

\footnotetext{
${ }^{98}$ Gusy, Christoph, Die Weimarer Reichsverfassung (Tübingen, Mohr Siebeck, 1997), p. VI.
} 
de la jurídica general. Pero como para aquello pueden ser necesarias aún algunas décadas, consideramos que el criterio formal es un buen criterio orientador. El derecho constitucional es una parte de la construcción social que abarcó de manera paulatina una serie de instituciones. Durante el siglo XIX coincide con la estatización del derecho, por lo que formular una distinción clara entre las fuentes formales de historia del derecho y de historia constitucional, no siempre es fácil. Por ello importa, en un principio, saber si los textos constitucionales recogen o no esa institución. En caso de haber una respuesta afirmativa a esa indagación, el contenido de la fuente es más determinante que su jerarquía. Del mismo modo, los principios propios del actual derecho público, elevados a nivel constitucional, como la juridicidad o el control a los gobernantes por parte de los gobernados, sirven de puente entre la historia del derecho y la constitucional. Importante es estudiar los derechos patrios en perspectiva comparada, pues dentro del constitucionalismo hay familias jurídicas, y algunas de estas son típicas y representativas de determinadas etapas del derecho constitucional ${ }^{99}$.

La doctrina y el derecho comparado juegan un rol fundamental, al relacionar los derechos constitucionales nacionales entre sí. Siempre hay algunos ordenamientos que van a la vanguardia a la hora de recepcionar nuevas tendencias y orientaciones políticas y sociales. A modo de ejemplo, sigue siendo poco entendible que las constituciones de Querétaro, Weimar y la URSS no sean debidamente estudiadas a la hora de investigar el derecho constitucional social, posterior a la primera guerra mundial, representante de la crisis del liberalismo decimonónico.

También es importante destacar que es labor de la historia constitucional y de la del derecho -si es que esta aspira a enriquecer el entendimiento de los actuales problemas del derecho público- entender la mentalidad jurídica pretérita. Si bien para algunos dicho entendimiento conlleva el riesgo de desdibujar los actuales principios inherentes a esta disciplina jurídica -como libertad, igualdad o democracia- es de toda justicia recrear el trayecto completo hasta el presente. Solo así se garantiza un grado de polifonía histórico constitucional. Recrear la mentalidad y las visiones de cada época sin temor a que estas no se condigan con los planteamientos del constitucionalismo norteamericano o francés posibilita visualizar no solo las diferentes formas de entender la Constitución, sino también ver cómo las ideas de cada una de las antedichas etapas del derecho constitucional fueron recepcionadas a nivel local. Más aún, dicho proceso refuerza los actuales principios, pues pone de manifiesto cuáles fueron los factores que los llevaron a detentar su actual posición dentro del sistema normativo. Tal fenómeno, propio de todo Occidente, muestra como a la larga, todos los sectores de la sociedad se apropiaron de las ideas del constitucionalismo.

Un punto conflictivo en esta diferenciación es qué rol le corresponde a la cultura jurídica de derecho público a partir de la Independencia. Lo que está fuera de discusión es que las ciencias jurídicas tienden a ser reactivas frente al cambio social. El cambio jurídico normalmente va la zaga. En todos los reinos

${ }^{99} \mathrm{La}$ ya mencionada constitución de Querétaro es representative de una nueva etapa del derecho constitucional. Algo similar ocurrió con la constitución federal mexicana de 1824 , modelo en el cual se inspiró el proyecto constitucional federal para Chile redactado por Infante. 
de América había ya a principios del siglo XIX una élite ilustrada que sostenía la necesidad de contar con una Constitución. Ella precedió a los textos jurídicos. Fue su impulsora y redactora. Pero la existencia de una élite con tales ideas no significa necesariamente que éstas fueran recogidas de manera acrítica. De ahí que no se puede estudiar esta época sin compenetrarse de las ideas de los líderes de opinión de esa élite ni sin analizar la enseñanza jurídica en las academias y facultades de derecho. Una cosa es el libro y otra muy distinta es cómo ese libro se interpreta. El uso social y la valoración de las constituciones son elementos que deben estar presentes; pero en base a ellos no se puede negar a un texto la calidad de Constitución, al menos en lo que respecta a la primera mitad del siglo XIX. En esa época hay un proceso de transición en el que las constituciones otorgadas no fueron pocas y en la que el primer objetivo político de estos documentos era, como se citó más arriba, poner atajo al pueblo. Por ello, no debería ser motivo de asombro que más de una constitución chilena de esa época haya tenido como fin principal mantener el orden o que este último haya sido más importante que las libertades. Lo importante de ese período fue que, a ambos lados del Atlántico, las constituciones ganaron prestigio y legitimidad.

También cabe cuestionarse cuánto de las ideas que sirvieron de base al constitucionalismo penetraron en otros grupos sociales distintos de la élite, y en caso de haber sucedido aquello, cómo fue entendida esa idea. Tal vez así se podría entender de mejor manera la diferencia entre el país legal y el país real.

Por esas razones, consideramos que entre los temas que cuentan con una dimensión constitucional habría que investigar los siguientes: codificación; principio de la libre circulación de la riqueza; estatuto de los aborígenes e igualdad; reformas legales y sustitución del derecho Indiano por el patrio en base al principio de igualdad; el paso del Estado misional al Estado confesional; los distintos modelos elaborados por la doctrina jurídica para describir la relación entre Estado e Iglesias en Europa y América; implementación de las reformas borbónicas en América indiana, antes y después de la independencia ${ }^{100}$; los pueblos originarios en el discurso independentista; el kraussimo en América hispana; los proyectos federales y la participación política; pervivencia de las formas de participación política indianas durante el siglo XIX; surgimiento y desarrollo del clericalismo y del militarismo; uso del derecho comparado como fuente para la redacción de cartas fundamentales, y la recepción e interpretación de publicistas latinoamericanos, europeos y norteamericanos en el mundo hispano parlante.

Lo anterior, además considerando que en Chile la discusión constitucional, a nivel doctrinario fue escasa y los cultores de esta disciplina relativamente pocos. De ahí que la discusión constitucional, la delimitación de las atribuciones de los poderes públicos y la formación del espacio público se diese al fragor de debates legales muy concretos. Por medio de ellos se puede reconstruir la historia constitucional y determinar qué fue y cuál o cuáles son las tradiciones constitucionales en Chile.

En las ciencias jurídicas no existen modelos puros y la realidad siempre supera

${ }^{100}$ La transformación de un sistema jurídico en otro, implica que en este caso el mismo fenómeno será estudiado por historiadores constitucionales e indianistas, pudiendo llegar los cultores de ambas disciplinas a resultados dispares, lo que no tiene nada de extraordinario. 
a la teoría. La solución de problemas concretos genera precedentes que guían el actuar de los operadores jurídicos. En muchos de los temas propuestos no hubo mención alguna al enciclopedismo francés o a los representantes del iusnaturalismo racionalista alemán, pero si se puede encontrar una construcción argumentativa y normativa que, apelando en parte al derecho tradicional y en parte al nuevo, a la doctrina y a elementos tradicionales, logró dar forma a nuevas realidades, más o menos valoradas por el ciudadano de a pie, que son las que terminan dando forma a la tradición constitucional.

\section{CONSIDERACIONES FINALES}

Con este artículo solo se ha pretendido contrastar la producción de la historiografía constitucional con las críticas y propuestas formuladas por autores de la talla de Maurizio Fioravanti y Bernd Marquardt, quienes postulan un nuevo enfoque que rescata el carácter internacional del derecho constitucional. En general, la obra histórico constitucional es escasa y descontinuada a lo largo del tiempo, fundada en meritorios esfuerzos individuales, donde cada obra destaca por su originalidad. Desgraciadamente, el nivel de ellas no es uniforme. Hay algunas a las que les corresponden plenamente las críticas formuladas por los profesores Fioravanti y Marquardt, así como hay tres autores a los que solo se les puede formular la crítica de poseer un enfoque exclusivamente nacional. Con la honrosa excepción de Sergio Carrasco, las fuentes y los hechos a analizar siguen siendo casi los mismos, por lo que en más de una ocasión lo que ha habido son nuevas interpretaciones de ellas. Un mayor énfasis en la doctrina y el derecho comparado y en los fenómenos propuestos permitiría reforzar la dimensión histórica del derecho constitucional, precisar mejor el actual desarrollo de garantías e instituciones y entender su vínculo con valores propios del derecho público y el constitucional. Así podríamos precisar mejor de qué hablamos cuando usamos el concepto de tradición constitucional y responder las preguntas acerca de la existencia de una o más tradiciones constitucionales en Chile. Por último, el criterio formal permite precisar contornos. De lo contrario se podría llegar al absurdo de que toda la historia del derecho en los siglos XIX y XX sea considerada historia constitucional.

Dos de los méritos de los iushistoriadores fue contribuir a superar la visión extrema del positivismo jurídico, especialmente en referencia al derecho indiano, e instalar el constitucionalismo gaditano como cuarto pilar del constitucionalismo moderno. En el ámbito de la historia constitucional, es importante recoger las críticas de un grupo de estudiosos de vanguardia, a fin de abrir nuevos campos y dar una mayor claridad conceptual a algunos conceptos muy citados, pero hasta hoy de contenido indeterminado. 


\section{BiBLIOGRAFÍA}

Alonso García, Gregorio, Ciudadanía católica. Identidad, exclusión y conflicto en la experiencia liberal hispana, en Molina APARICIO, Fernando (ed.) Extranjeros en el pasado. Nuevos historiadores de la España contemporánea (Bilbao, Universidad del País Vasco, 2009), pp. 45-72.

ANDRADES, Eduardo, "La incultura en la que España mantenía a sus colonias", Dos tópicos del mito fundacional republicano en Chile, en REHJ., 40 (2018), pp. 283-308.

Barrientos, Javier, La Constitución de Cádiz en Chile, en Escudero, José (ed.), Cortes y Constitución de Cádiz. 200 años (Madrid, Fundación Rafael del Pino, 2011), III, pp. 674-699.

BraHm, Enrique, Mariano Egana: derecho y politica en la fundación de la República conservadora (Santiago, Ediciones Centro de Estudios Bicentenario, 2007).

Bravo, Bernardino, Constitución y reconstitución: historia del Estado en Iberoamérica (siglos XVI al XIX) (Santiago, Abeledo Perrot-Legal Publishing).

- Una historia jamás contada. Chile 1811-2011. Cómo salió dos veces adelante (Santiago, Ediciones Origo, 2016).

BRICEÑO, Ramón, Memoria histórico-crítica del derecho público chileno desde 1840 hasta nuestros días. Obra presentada a la Universidad de Chile en la sesión solemne del 14 de octubre de 1849, con la que celebró el sexto aniversario de su instalación (Santiago, Imprenta de Julio Belin y compañía, 1849).

Callies, Christian; Ruffert, Matthias (eds.), EUVIAEUV Das Verfassungsrecht der Europäischen Union mit Europäischer Grundrechtecharta (München, Verlag C.H. Beck, 2011).

Campos, Fernando, Historia constitucional de Chile (Santiago, Editorial Jurídica de Chile, 1956).

Carrasco, Manuel, Comentarios a la Constitución de 1833 (Valparaíso, Imprenta y Librería El Mercurio, 1858).

Carrasco, Sergio, Génesis y vigencia de los textos constitucionales chilenos ${ }^{3}$ (1983, Santiago, Editorial Jurídica de Chile, 2002).

Cristi, Renato; Ruiz-Tagle, Pablo, La República en Chile. Teoría y práctica del constitucionalismo republicano (Santiago, Editorial LOM, 2006).

Donoso, Ricardo, Las ideas políticas en Chile (México, Fondo de Cultura Económica, 1946).

Dougnac, Antonio, Del Derecho indiano al patrio: el tránsito del magistrado Juan de Dios Vial del Río (1774-1850), en Revista Chilena de Historia del Derecho, 19 (2003), pp. 63-133.

- El sistema jurídico indiano en el constitucionalismo chileno durante la patria vieja (1810-1814), en REHJ., 22 (2000), pp. 225-266.

Dougnac, Antonio; Vicencio, Felipe, La Escuela Chilena de Historiadores del Derecho y los estudios jurídicos en Chile (Santiago, Facultad de Ciencias Jurídicas y Sociales de la Universidad Central, 1999-2000) 2 vols.

EgaÑa, Juan, Memoria política sobre si conviene en Chile la libertad de cultos (Caracas, Imprenta Devisme, 1829).

Errázuriz, Federico, Chile bajo el imperio de la Constitución de 1828. Memoria histórica que debió ser leida en la sesión solemne que la Universidad de Chile hubo de celebrar en 1860 (Santiago de Chile. Imprenta Chilena, 1861). 
ERrázuriz, Isidoro, Historia de la administración Errázuriz (Valparaíso, Imprenta La Patria, 1877).

Eyzaguirre, Jaime, Historia constitucional de Chile (Santiago, Editorial Universitaria, 1959).

Fioravanti, Maurizio, Constitución: de la Antigüedad a nuestros días ${ }^{2}$ (2002, Madrid, Editorial Trotta, 2007).

Galdames, Luis, Evolución constitucional de Chile. 1810-1925 (Santiago, Imprenta y Litografía Balcells, 1925).

GarCía, José, La tradición constitucional de la P. Universidad Católica de Chile (Santiago, Ediciones de la Pontificia Universidad Católica de Chile, 2017).

GusY, Christoph, Die Weimarer Reichsverfassung (Tübingen, Mohr Siebeck, 1997).

GuZMÁn Brito, Alejandro, La codificación civil en Iberoamérica. Siglos XIX y XX (Santiago, Editorial Jurídica de Chile, 2000).

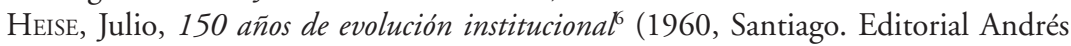
Bello, 1989).

- Años de formación y aprendizaje político: 1810-1833 (Santiago, Editorial Universitaria, 1978).

- Historia constitucional de Chile ${ }^{2}$ (1950, Santiago, Editorial Jurídica de Chile, 1954).

Hunneus, Antonio, La Constitución de 1833. Ensayo sobre nuestra historia constitucional de un siglo. Publicado en la Revista Chilena de Historia y Geografía. Estudios Chilenos. Corregido (Santiago, Editorial Splendid, 1933).

InFANTE, Javier, Autonomía, independencia y república en Chile, 1810-1828 (Santiago de Chile. Ediciones del Centro de Estudios Bicentenario, 2014).

Jarass, Hans, EU-Grundrechte: ein Studien-und Handbuch (München, Verlag C.H.Beck, 2005).

JelLineK, Georg, Vorlesungsmitschrift von Max Ernst Mayer aus dem Sommersemester 1896 (Tübingen, Mohr Siebeck, 2016).

JoCELYN-Holt, Alfredo, La independencia de Chile: tradición, modernización y mito ${ }^{2}$ (1992, Santiago, Ediciones DeBolsillo, 2009).

LASTARrIA, José Victorino, Historia constitucional del medio siglo: revista de los progresos de los sistemas representativos en Europa i América durante los primeros cincuenta años del siglo XIX: primera parte de 1800 a 1825 (Valparaíso, Imprenta El Mercurio, 1853).

- Investigaciones sobre la influencia social de la conquista y el sistema colonial de los españoles en Chile (Santiago, Anales de la Universidad de Chile, 1844).

- Lecciones de politica positiva profesadas en la Academia de Bellas Letras (Santiago, Imprenta de El Ferrocarril, 1874).

LÓpez, Alí, La real audiencia de Caracas (Mérida, Ediciones del Rectorado de la Universidad de los Andes, 1998).

Marquardt, Bernd, Los dos siglos del estado constitucional en América Latina (18102010): historia constitucional comparada (Bogotá, Universidad Nacional de Colombia, Facultad de Derecho, Ciencias Políticas y Sociales. Instituto Unidad de Investigaciones "Gerardo Molina”-UNIJUS, 2011).

Martínez, Sergio, La residencia en el derecho patrio chileno, en Revista Chilena de Historia del Derecho, 4 (1965), pp. 129-207.

MezA, Néstor, Conciencia política chilena durante la monarquía (Santiago, Instituto de Investigaciones Histórico-Culturales, Facultad de Filosofía y Educación, Universidad de Chile, 1958).

MezA, Néstor, La actividad política en el reino de Chile (1806-1810) (Santiago, Insti- 
tuto de Investigaciones Histórico-Culturales, Facultad de Filosofía y Educación, Universidad de Chile, 1956).

Oyarzún, Luis, El pensamiento de Lastarria, en VV.AA., Estudios sobre José Victorino Lastarria (Santiago, Ediciones de la Universidad de Chile, 1988).

Palma, Eric, Estado constitucional liberal católico en Chile (1812-1924) Nueva historia constitucional (Santiago, Orión, 2011).

SANTA María, Domingo, Vida de don José Miguel Infante (Santiago, Imprenta Chilena, 1853).

Valencia Avaria, Luis (1986) Anales de la República: textos constitucionales de Chile y registro de los ciudadanos que han integrado los poderes ejecutivo yy legislativo desde 1810 (Santiago, Editorial Andrés Bello, 1986) 2 vols.

Westermeyer, Felipe, La historia del derecho en la obra del jurista y político liberal chileno José Victorino Lastarria, en REHJ., 37 (2015), pp. 295-321. 